\title{
How Should Aerosols Be Delivered During Invasive Mechanical Ventilation?
}

\author{
Rajiv Dhand MD FAARC
}

\author{
Introduction \\ Aerosol Delivery Devices in Ventilator-Supported Patients \\ Pressurized Metered-Dose Inhalers \\ Nebulizers \\ Soft Mist Inhaler \\ Dry Powder Inhaler \\ Intratracheal Nebulizing Catheter \\ Choice of Aerosol Delivery Device in Mechanically Ventilated Patients \\ Drugs Administered via Inhalation to Mechanically Ventilated Patients \\ Goal-Directed Aerosol Therapy in Mechanically Ventilated Patients \\ Assure Drug Delivery \\ Optimize Drug Deposition in the Lung \\ Provide Consistent Dosing \\ Avoid Inappropriate Therapies \\ Provide Reproducibility of Dosing \\ Employ Clinically Feasible Methods \\ Enhance Safety \\ Control Costs \\ Summary
}

The delivery of aerosols to mechanically ventilated patients presents unique challenges and differs from inhaled drug delivery in spontaneously breathing patients in several respects. Successful aerosol delivery during invasive mechanical ventilation requires careful consideration of a host of factors that influence the amount of drug inhaled by the patient. Pressurized metered-dose inhalers and nebulizers (jet, ultrasonic, and vibrating mesh) are the most commonly used aerosol delivery devices in these patients, although other delivery devices, such as dry powder inhalers, soft mist inhalers, and intratracheal nebulizing catheters, could also be adapted for in-line use. Bronchodilators, inhaled corticosteroids, antibiotics, pulmonary surfactant, mucolytics, biologicals, genes, prostanoids, and other agents are administered by inhalation during mechanical ventilation for a variety of indications. The goals of inhalation therapy during mechanical ventilation could be best achieved by (1) assuring drug delivery; (2) optimizing drug deposition in the lung; (3) providing consistent dosing; (4) avoiding inappropriate therapies; (5) achieving reproducible dosing; (6) employing clinically feasible methods; (7) enhancing the safety of inhaled drugs; and (8) controlling costs of aerosol therapy. The techniques of administration of aerosols with various delivery devices during mechanical ventilation are well known, but there continues to be significant variation in clinical practice and guidelines are needed to provide best practices for a wide range of clinical settings encountered in mechanically ventilated patients. Key words: inhalation therapy; nebulizers; aerosol therapy; bronchodilators; respiratory failure. [Respir Care 2017;62(10):1343-1367. (c) 2017 Daedalus Enterprises] 


\section{Introduction}

In the United States, it is estimated that, annually, more than 700,000 adults admitted to the hospital require mechanical ventilation, ${ }^{1}$ and many of these patients receive treatments by inhalation. In the past, it was widely believed that aerosolized therapies were unlikely to be successful in mechanically ventilated patients because of the extremely poor efficiency of drug delivery in this setting. ${ }^{2}$ Many barriers, especially the inability of drug particles to negotiate the ventilator circuit and endotracheal tube (ETT), were thought to preclude effective aerosol delivery to ventilator-supported patients, and this view was corroborated by landmark studies that found low pulmonary deposition of aerosolized drugs in this patient population compared to ambulatory, non-intubated patients. ${ }^{3,4}$ The complexity of aerosol therapy in ventilator-dependent patients is due to the interaction of a host of factors that determine drug deposition in the lung. During the past two decades, impressive gains in knowledge about the interplay of these factors, (eg, humidity, duty cycle, and device configuration and placement in the circuit) have contributed immensely to improved methods for aerosol delivery. ${ }^{5}$ Indeed, we have learned a great deal about the optimal techniques to achieve adequate drug deposition in the lung with both pressurized metered-dose inhalers (pMDIs) and nebulizers. Moreover, newer designs of portable, battery-operated nebulizers that employ a vibrating mesh to generate aerosol ${ }^{6}$ and hydrofluoroalkane (HFA)propelled pMDIs ${ }^{7,8}$ have made a significant impact on the efficiency of aerosol delivery during mechanical ventilation. The efficiency of drug delivery to the lung in such patients could now match or surpass the efficiency of aerosol drug delivery in spontaneously breathing patients. ${ }^{9}$

The remarkable increase in knowledge about aerosol deposition in mechanically ventilated patients resulted from the confluence of three sets of in vitro and in vivo studies that each corroborated the other's findings. First, bench models of mechanical ventilation made invaluable contributions to elucidating the effects of multiple variables on the efficiency of aerosol delivery and in maximizing drug delivery to the lung. Such in vitro studies with both pMDIs

Dr. Dhand presented a version of this paper in the New Horizons Symposium at the AARC Congress 2016, held October 15-18, 2016, in San Antonio, Texas.

Dr Dhand discloses relationships with Bayer, AstraZeneca, GSK, and Sunovion.

Correspondence: Rajiv Dhand MD FAARC, Department of Medicine, University of Tennessee Graduate School of Medicine, 1924 Alcoa Highway, U-114, Knoxville, TN 37920. E-mail: rdhand@utmck.edu.

DOI: $10.4187 /$ respcare. 05803 and nebulizers demonstrated that with pMDIs, the drug output is well defined, and several elegantly performed investigations enabled a fairly precise prediction of the amount of drug delivered to the lung. ${ }^{10,11}$ Similarly, the amount of drug delivered to the lung with a nebulizer could also be estimated under specified conditions of nebulizer operation. ${ }^{12}$ With the nebulizer synchronized to operate during inspiration, the drug output per minute determined with specific ventilatory parameters (tidal volume, air flow, inspiratory time/total duration of the breath) could be employed to accurately estimate the time required to deliver a specified amount of drug. ${ }^{12}$ Therefore, the ability to control circuit conditions, ventilatory parameters, and conditions of nebulization could allow estimation of drug delivery with various nebulizers that differ in their operational efficiency. By measuring exhaled aerosol during administration of albuterol from a pMDI with a spacer chamber using an in vitro model simulating adult breathing patterns, and measuring the amount of aerosol exhaled from mechanically ventilated patients under similar conditions, Fink and colleagues ${ }^{11}$ found that $4.8 \%$ more drug was exhaled in vivo than in vitro. By subtracting the $4.8 \%$ difference in exhaled aerosol from the in vitro lung delivery of $16.2 \%$, the adjusted in vitro deposition was $11.4 \%$. This value $(11.4 \%)$ is remarkably similar to the calculated deposition of $10.8 \%$ of radiolabeled aerosol in mechanically ventilated patients using a pMDI with a spacer chamber under similar ventilator conditions after adjusting for tissue adsorption of radioactivity. ${ }^{4}$ Likewise, studies with nebulizers found that aerosol deposition in the lower respiratory tract measured by a mass balance technique was $\sim 15 \% .{ }^{13}$ These in vitro studies showed remarkable consistency in the values of lung deposition with various devices.

Second, in ventilated patients, estimation of plasma levels of drugs administered by a pMDI/nebulizer reflects lower respiratory tract deposition because the ETT prevents the inhaled drug from depositing in the oropharynx and subsequently being absorbed via the gastrointestinal tract. There is the potential for exhaled drug to bypass the ETT cuff and deposit in the oropharynx, but this amount is generally minimal and should not contribute significantly to the plasma levels. After administration of albuterol with a pMDI and spacer, the area under the concentration-time curve was only marginally lower in the subjects than in healthy controls. ${ }^{14}$ Moreover, measurement of urinary albuterol excretion in ventilated subjects with normal renal function showed that albuterol recovery was highest (38\%) after administration with a pMDI and chamber spacer, intermediate (16\%) with a nebulizer, and lowest (9\%) with a pMDI and right angle port connected to the ETT. ${ }^{15}$ These findings were similar to predictions based on previous in vitro studies. Furthermore, measurement of antibiotic levels in tracheal aspirates from mechanically ventilated 
subjects after administration with a nebulizer were shown to corroborate the effects of humidity on aerosol delivery that were previously described in vitro. ${ }^{16}$

Third, in mechanically ventilated subjects, significant bronchodilator effects occurred after administration of 4 puffs $(400 \mu \mathrm{g})$ with a pMDI ${ }^{17}$ or $2.5 \mathrm{mg}$ of albuterol with a standard nebulizer (Fig. 1). ${ }^{18,19}$ Minimal therapeutic advantage was gained by administering higher doses, whereas the potential for adverse effects was increased. ${ }^{17,19,20}$ In

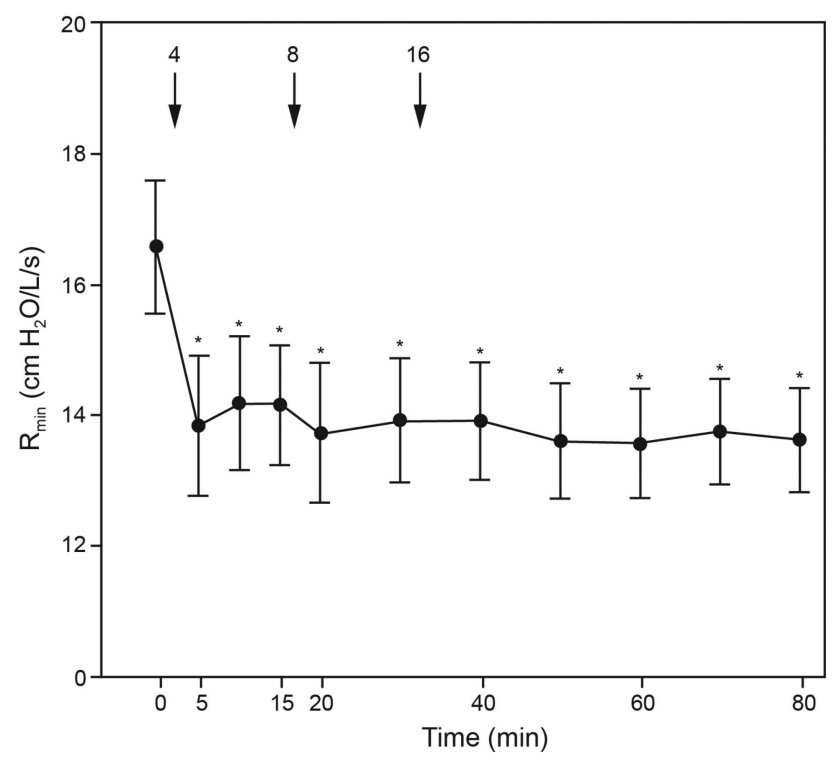

Fig. 1. Effect of albuterol on minimal inspiratory resistance in 12 stable mechanically ventilated subjects with COPD. Significant decreases in minimal inspiratory resistance occurred within 5 min of administration of 4 puffs of albuterol. The addition of 8 and 16 puffs (cumulative doses of 12 and 28 puffs, respectively) did not achieve a significantly greater effect than that with 4 puffs $(P>.05)$. Bars represent SE. ${ }^{*} P<.001$. From Reference 17, with permission. certain clinical settings, higher doses of bronchodilators may be needed in patients with severe airway obstruction or if the technique of administration is not optimal. With a carefully executed technique of administration, most stable mechanically ventilated subjects with COPD achieved near maximal bronchodilation after administration of 4 puffs of albuterol with a pMDI or $2.5 \mathrm{mg}$ with a nebulizer. ${ }^{18}$ (Fig. 2) Thus, the dose needed for obtaining effective bronchodilation in ventilator-supported patients was similar to the doses employed with pMDIs and nebulizers in spontaneously breathing patients. ${ }^{21}$

The distinction between spontaneously breathing and mechanically ventilated patients was observed in the duration of the bronchodilator response, which appears to be shorter in duration in stable mechanically ventilated patients with COPD than in ambulatory patients $(2-3 \mathrm{~h}$ vs $4-6 \mathrm{~h}$, respectively). ${ }^{18,22}$ Thus, ventilated patients require scheduled administration of short-acting $\beta$-agonist bronchodilator (albuterol) every 3-4 h.

These earlier studies provided evidence that subtle differences in the technique of administration produced marked variations in the efficiency of inhaled drug delivery. ${ }^{5}$ However, if careful attention was given to the technique of administration and the dose of drugs was increased to account for the effect of heat and humidification, adequate amounts of drugs could be delivered to the lungs of mechanically ventilated patients to achieve meaningful therapeutic effects. ${ }^{17-20,22}$

\section{Aerosol Delivery Devices in Ventilator-Supported Patients}

Delivery of aerosols to mechanically ventilated patients differs from that in spontaneously breathing

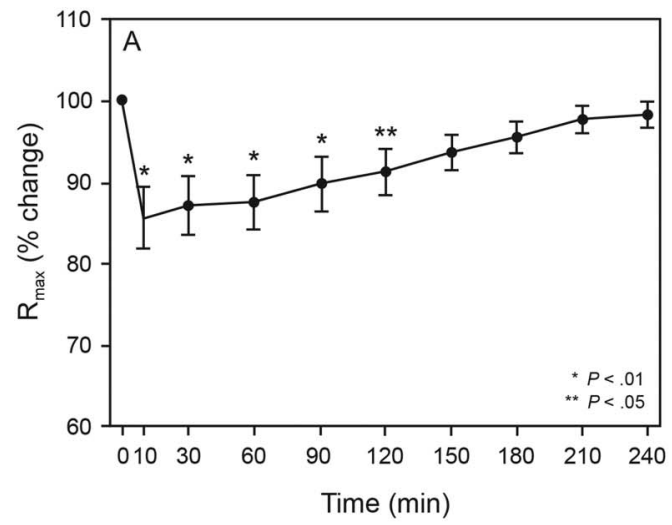

Fig. 2. Effect of albuterol on maximum inspiratory airway resistance $\left(R_{\max }\right)$ in stable, mechanically ventilated subjects with COPD. There was a decrease in airway resistance from baseline values within $10 \mathrm{~min}$ of albuterol administration. A: Change in airway resistance from baseline (time 0 ) after 4 doses of albuterol from a pressurized metered-dose inhalers (pMDI). B: Change in airway resistance from baseline (time 0 ) after $2.5 \mathrm{mg}$ of albuterol given by nebulizer. Significant reductions in airway resistance were sustained for $2 \mathrm{~h}$ and returned to baseline by $4 \mathrm{~h}$. The response to albuterol administered by pMDI $(0.4 \mathrm{mg})$ was comparable to that achieved with 2.5 mg administered by nebulizer. Bars represent SEM. ${ }^{\star} P<.01 .{ }^{* *} P<.05$. From Reference 18. 
Table 1. Differences in Aerosol Delivery in Spontaneously Breathing Versus Mechanically Ventilated Patients

\begin{tabular}{|c|c|c|}
\hline & Spontaneously Breathing Patient & Mechanically Ventilated Patient \\
\hline Position of the patient & Sitting or standing & Supine or semi-recumbent \\
\hline Aerosol generator & pMDI/pMDI and spacer/dry powder inhaler/nebulizer & pMDI and spacer/nebulizer \\
\hline Method of delivery & By mouthpiece/facemask & $\begin{array}{l}\text { Connected to endotracheal tube/inspiratory limb of } \\
\text { ventilator circuit }\end{array}$ \\
\hline Humidity & Ambient humidity & Humidifed ( $\sim 97 \%$ relative humidity) \\
\hline Temperature & Room/ambient & Warmed to $\sim 35^{\circ} \mathrm{C}$ \\
\hline Inspiratory airflow & Sinusoidal & Constant or ramp flow \\
\hline Breath configuration & Controlled by patient & Controlled by ventilator* \\
\hline Aerosol administration & Self-administered & Administered by nurse/therapist \\
\hline Airway & Oral/nasal cavity and upper airway & Artificial airway \\
\hline
\end{tabular}

\footnotetext{
* In mandatory modes of mechanical ventilation, the ventilator controls the breath configuration. In spontaneous modes of ventilation, the breath configuration is influenced by the patient's effort pMDI $=$ pressurized metered-dose inhaler

Adapted from Reference 23.
}

patients in several respects (Table 1). ${ }^{23}$ The key difference is that the administration of aerosols is usually dependent on the patient when they are spontaneously breathing. In contrast, aerosols are administered to ventilator-dependent patients by a member of the clinical team, usually a nurse or respiratory therapist, that is taking care of the patient.

\section{Pressurized Metered-Dose Inhalers}

pMDIs are commonly used for administering inhaled drugs to mechanically ventilated patients because they are considered to be cost-effective, convenient, reliable, and safe. ${ }^{24,25}$ All pMDIs are designed as closed systems consisting of a meter-valved canister to be used with a unique actuator mouthpiece that is designed specifically for that canister. These actuators do not lend themselves to use in closed pressurized circuits such as those commonly utilized for mechanical ventilation. Consequently, third-party actuator devices that allow the pMDIs to be connected in-line in closed, pressurized circuits are used during mechanical ventilation. These devices range from simple adapters with a port and a single nozzle to more complex spacer chambers. ${ }^{25}$ Performance varies between adapter designs, and for the same adapter type between pMDI formulations, depending on both the drug and the propellants used. ${ }^{26}$ During mechanical ventilation in a dry unheated ventilator circuit, an in vitro study with three different setups were tested: an elbow adapter at the ETT; an in-line spacer chamber placed on the inspiratory limb just before the $\mathrm{Y}$ adapter; and the in-line chamber placed between the $\mathrm{Y}$ and ETT. The pMDI with elbow adapter delivered the lowest amount of drug (7.3\%), while the chamber delivered $32.1 \%$ at the inspiratory limb and $29 \%$ of the nominal dose when placed at the ETT. ${ }^{27}$ Using a chamber-shaped spacer with the pMDI resulted in 4- to 6-fold greater aerosol drug delivery when compared with either an elbow adapter or a unidirectional in-line spacer. ${ }^{4,27,28}$ In contrast, the efficiency of a bidirectional in-line spacer was higher than the efficiency of a unidirectional in-line spacer and achieved comparable efficiency with chamber spacers. ${ }^{26}$

The efficiency of drug delivery with pMDIs is very dependent on the configuration of the device and technique of administration. In vitro studies have shown that aerosol drug delivery to the lower respiratory tract can vary from $0.3 \%$ to $97.5 \%$ with pMDIs. . $^{3,10,11,27,29-31}$ Therapy with pMDIs can be ineffective if careful attention is not given to the appropriate technique of administration. ${ }^{19}$

All pMDIs require shaking and priming, with several actuations to room air prior to first use and after extended periods of time between uses. ${ }^{32}$ With the transition to HFA propellants, recommended periods between priming have been extended up to several days. However, the failure to shake a pMDI canister that has been standing overnight may decrease total emitted and respirable dose by as much as $25 \%$ and $35 \%$, respectively. ${ }^{33}$ After appropriately shaking a pMDI, up to 8 actuations from a pMDI can be administered without a reduction in emitted dose, ${ }^{10}$ and the emitted dose after actuation at 15 -s intervals is similar to the dose emitted with actuation at the manufacturer recommended 1-min intervals. ${ }^{10}$ A nozzle extension to the pMDI in the form of a fine catheter that traverses the length of the ETT has been proposed as a method to enhance the efficiency of drug delivery to the lower respiratory tract. ${ }^{29,34}$ With this delivery system, there are concerns about catheter blockage and mucosal damage induced by propellants, surfactants, or other constituents of the pMDI formulation. ${ }^{35}$

Connecting the pMDI to a spacer chamber placed in the inspiratory limb of the ventilator circuit $15 \mathrm{~cm}$ from the ETT increases aerosol deposition with improved potential 
Table 2. Optimal Technique for Drug Delivery by pMDI in Ventilated Patients

\footnotetext{
1. Have patient seated in erect or semi-erect position.*

2. Review order, identify patient, and assess need for bronchodilator.

3. Suction endotracheal tube and airway secretions.

4. Shake pMDI and warm to hand temperature.

5. Place pMDI in space chamber adapter in ventilator circuit about $15 \mathrm{~cm}$ from endotracheal tube.

6. Remove HME. Do not disconnect humidifier.

7. Ensure that there is no leak in the circuit.

8. Coordinate pMDI actuation with beginning of inspiration.

9. Wait at least 15 seconds between actuations; administer total dose.

10. Monitor for adverse response.

11. Reconnect HME.

12. Document clinical outcome.
}

* Unless there is a clinical contraindication to elevating the head of the patient. pMDI $=$ pressurized metered-dose inhaler

$\mathrm{HME}=$ heat and moisture exchanger

for clinical response. ${ }^{28,36}$ Ari and colleagues, using a heated/humidified in vitro model of adult ventilation, quantified the percent of emitted dose delivered distal to a ETT from an albuterol pMDI with chamber adapter, in each of three positons: between ETT and Y-piece (7.6 $\pm 1.3 \%)$, in the inspiratory limb $15 \mathrm{~cm}$ from the $\mathrm{Y}$-piece $(17.0 \pm 1.0 \%)$, and $15 \mathrm{~cm}$ from the ventilator before the inlet of the humidifier $(2.5 \pm 0.8 \%) .{ }^{37}$ On the basis of these studies, the pMDI and chamber spacer should be placed at a distance of $15 \mathrm{~cm}$ from the Y-piece.

In summary, the pMDI offers a safe and effective method for administration of medications to the lungs of ventilator-dependent patients. The use of a pMDI is an excellent option for prescribed drugs that are available in this dosage form, and the delivery of 4 to 8 puffs provides the desired clinical response. Attention to detail such as the type of actuator used, placement in the ventilator circuit, and timing of actuation are required to optimize therapy (Table 2).

\section{Nebulizers}

Three principal designs of nebulizers are employed to deliver medications to mechanically ventilated patients: (1) jet nebulizers, (2) ultrasonic nebulizers, and (3) vibrating mesh nebulizers.

Jet Nebulizers. In a jet nebulizer, a jet of compressed air or oxygen under high pressure passes through a narrow opening near the tip of a capillary tube whose base is immersed in the drug solution to be nebulized. ${ }^{38,39}$ The low pressure created by the expansion of the jet draws the liquid up the capillary tube. The shearing force of the jet stream produces a liquid film that breaks up into small droplets secondary to surface-tension forces. Larger particles deposit on a baffle placed upstream of the aerosol stream and on the walls of the nebulizer, whereas the smallest droplets leave the nebulizer. In a mechanical ventilator circuit, the resulting aerosol is carried into the stream of gas from the ventilator to the patient. ${ }^{39}$

Jet nebulizers are easy to use and inexpensive compared with mesh and ultrasonic nebulizers. However, use of a jet nebulizer during mechanical ventilation entrains an additional 6-8 L/min of gas into the ventilator circuit, which influences the tidal volume delivered to the patient. Jet nebulizers may also inactivate or denature the drug due to shear forces. ${ }^{38,40}$ Other disadvantages of jet nebulizers are the requirement for a power source, inconveniently long treatment time, need for equipment set up and cleaning, and significant variations in the performance of various nebulizers, both within the same brand and across different brands. ${ }^{41-43}$ Therefore, it is important to characterize the efficiency of a jet nebulizer before using it to deliver aerosolized drugs to mechanically ventilated patients. Jet nebulizers continue to be commonly employed in ventilatorsupported patients because of familiarity with their use, ease of operation, and low cost.

Ultrasonic Nebulizers. Ultrasonic nebulizers also use electricity in creating high-frequency vibrations that are transferred to the surface of the solution to be aerosolized. A standing wave is created in the liquid and droplets breaking off from the crest of this wave generate an aerosol. The higher the frequency of vibration, the smaller the particle size generated, and the higher the amplitude of vibrations, the higher is the drug output delivered to the patient. ${ }^{38}$ Although there are several brands of ultrasonic nebulizers available for use in mechanically ventilated patients, they have not been routinely employed in this clinical setting due to problems associated with their use such as their bulk, relative inefficiency, high cost, inability to aerosolize viscous solutions, settling of suspensions, and larger particle size. ${ }^{44-46}$ Another problem with ultrasonic nebulizers is that the drug solution becomes more concentrated during operation, and the solution temperature increases by $10-15^{\circ} \mathrm{C}$ after a few minutes of ultrasonic nebulization. ${ }^{44,45}$ The increase in temperature has the potential to denature some drug formulations.

Several commercial brands of ultrasonic nebulizers have been adapted for aerosol delivery with specific ventilators. ${ }^{31,47-49}$ Most ultrasonic nebulizers have a higher rate of nebulization and require a shorter time of operation than jet nebulizers. ${ }^{48}$ To overcome the problem of size, smallervolume ultrasonic nebulizers with smaller residual volumes than jet nebulizers have been employed. ${ }^{44,48,50}$

Placement of ultrasonic nebulizers proximal or distal to the Y-piece in the ventilator circuit does not influence the efficiency of aerosol delivery. ${ }^{31,51}$ Likewise, placing the 
ultrasonic nebulizer in the inspiratory limb of the ventilator circuit $50 \mathrm{~cm}$ from the Y-piece did not improve its efficiency. ${ }^{51}$ The efficiency of aerosol delivery with ultrasonic nebulizers could be modestly improved by using a longer inspiratory time, by reducing the minute ventilation, and by employing a lower breathing frequency. ${ }^{31,51}$ Notably, the efficiency of aerosol delivery with ultrasonic nebulizers is doubled by the addition of a cylindrical storage chamber (volume, $500-600 \mathrm{~mL}$ ) in the inspiratory limb of the ventilator circuit. ${ }^{31,51}$

Vibrating Mesh Nebulizers. Vibrating mesh nebulizers employed during mechanical ventilation are newer and more efficient than jet or ultrasonic nebulizers. These nebulizers employ batteries or electricity to vibrate a piezoelectric crystal and move the liquid drug through a micron mesh at a very high frequency to generate aerosols. . $^{6,46,52-56}$ The diameter of the mesh affects the particle size of aerosols produced by vibrating mesh nebulizers. Vibrating mesh nebulizers are more efficient than jet nebulizers because of their small residual volume (ranging from $0.1 \mathrm{~mL}$ to $0.5 \mathrm{~mL}$ ). Because aerosols produced by vibrating mesh nebulizers have a higher respirable fraction, the nominal dose of drugs to be administered for clinical response could be reduced compared to jet or ultrasonic nebulizers. $6,52,56,57$ Also, vibrating mesh nebulizers are quieter than jet nebulizers. Because vibrating mesh nebulizers neither cool nor heat the solution, there is minimal risk of denaturation, and they are thus recommended for use with complex microstructures and large molecules. ${ }^{58,59}$ Suspensions or viscous drugs could clog the pores of the mesh nebulizer without making a noticeable difference to the nebulizer output. ${ }^{60}$ Despite concerns about the consistency with which some vibrating mesh nebulizers deliver the volume placed in the reservoir, ${ }^{61}$ their popularity for aerosol delivery in mechanically ventilated patients has grown. ${ }^{62}$ Some manufacturers, such as the Hamilton SI and G5 ventilators, have integrated Aerogen's aerosol drug delivery technology. Aerogen's Aeroneb Solo nebulizer is now available as an integrated unit with the Maquet Servo-i ventilator. ${ }^{63}$

A breath-synchronized vibrating mesh nebulizer, the Pulmonary Drug Delivery System (PDDS) Clinical is a single-use drug delivery system that is primarily designed for delivery of aerosolized medications to mechanically ventilated patients. ${ }^{64}$ Therapy with the PDDS could be continued when a patient is able to breathe spontaneously and has been successfully extubated. The device could also be employed for inhalation therapy in patients receiving noninvasive ventilation. Aerosol generation is synchronized to a specific portion of the inspiratory cycle by a control module that operates from an AC/DC adapter. A pressure transducer measures airway pressure in the inspiratory limb of the ventilator circuit. During mechanical ventilation, a rise in airway pressure signals the onset of mechanical pressure from the ventilator and is sensed by the microprocessor in the control module to provide power to the nebulizer during a specific portion of the inspiratory cycle. The controller has 2 software algorithms, one for use during mechanical ventilation and the other for use when the patient is off the ventilator. In the spontaneous breathing mode, the control module operates in a simple, breath-synchronized mode, and it generates aerosol during the entire inspiratory phase. For this purpose, the pressure transducer monitors the fall in airway pressure during inspiration. The PDDS Clinical is being investigated for delivery of inhaled amikacin in patients with ventilatorassociated pneumonia. ${ }^{65}$

Factors Influencing Drug Delivery via Nebulizers. Aerosol drug delivery from a nebulizer to the distal airways/alveoli of a mechanically ventilated patient is not only influenced by the type of nebulizer employed, but also by residual volume, mode of nebulization, position of the nebulizer in the ventilator circuit, gas flow, and bias flow in the circuit. ${ }^{9}$ Such factors influence the emitted dose and make it difficult to provide objective comparisons of clinical outcomes.

Residual volume (also termed dead volume) is the amount of medication remaining in the nebulizer at the end of a treatment. The residual volume can range from $0.1 \mathrm{~mL}$ to $2.4 \mathrm{~mL}$ depending on the type of nebulizer used for the treatment. The greater the residual volume, the lower will be the amount of drug that is nebulized. Generally, ultrasonic and vibrating mesh nebulizers have smaller residual volumes than jet nebulizers. $48,50,56,61,64$ For jet nebulizers, it is recommended to use a fill volume of $4-5 \mathrm{~mL}$ if the nebulizer is not specifically designed for a smaller fill volume. ${ }^{43}$ This precaution increases the treatment time, while diluting the medication and allowing for a greater proportion to be nebulized during mechanical ventilation.

Each brand of jet nebulizer is designed to work best at a specific flow, ranging from $2 \mathrm{~L} / \mathrm{min}$ to $8 \mathrm{~L} / \mathrm{min}$, which should be specified by the manufacturer. Operating any jet nebulizer at a lower flow or pressure will increase the particle size of the aerosol produced. Gas flow and nebulization time are inversely related. Although operating a jet nebulizer at a higher gas flow will decrease treatment time needed to deliver the specified amount of drug to mechanically ventilated patients, it can be detrimental because higher gas flows may increase the delivered tidal volume. The tidal volume needs to be adjusted to account for this additional volume, but this correction is not precise. In contrast to jet nebulizers, ultrasonic and vibrating mesh nebulizers are operated by electricity and are not influenced by gas flow. The techniques of operating jet and vibrating mesh nebulizers in patients receiving mechanical ventilation are described in Tables 3 and 4, respectively. 
Table 3. Optimal Technique for Drug Delivery by Jet Nebulizer in Ventilated Patients

1. Have the patient seated in an erect or semi-erect position.*

2. Review order, identify patient, and assess need for bronchodilator.

3. Suction endotracheal and airway secretions.

4. Place drug in nebulizer to fill volume of $4-6 \mathrm{~mL}$.

5. Place nebulizer in the inspiratory line 18 in $(46 \mathrm{~cm})$ from the patient Y-piece.

6. Turn off flow-by or continuous flow during nebulizer operation.

7. Remove HME from circuit (do not disconnect humidifier).

8. Set gas flow to nebulizer at $6-8 \mathrm{~L} / \mathrm{min}$.

a. Use a ventilator if it meets the nebulizer flow requirements and cycles on inspiration, or

b. Use continuous flow from external source $(\sim 50 \mathrm{psi})$.

9. Adjust ventilator volume or pressure limit to compensate for added flow.

10. Tap nebulizer periodically until nebulizer begins to sputter.

11. Remove nebulizer from circuit, rinse with sterile water and run dry, store in safe place.

12. Reconnect humidifier or HME, return ventilator settings and alarms to previous values.

13. Monitor patient for adverse response.

14. Assess outcome and document findings.

* Unless there is a clinical contraindication to elevating the head of the patient. HME $=$ heat and moisture exchanger

Table 4. Optimal Technique for Drug Delivery by Vibrating Mesh Nebulizer in Ventilated Patients

1. Correctly assemble the nebulizer.

2. Follow the manufacturer's instructions in performing a functionality test prior to the first use of a new nebulizer as well as after each disinfection to verify proper operation.

3. Pour the solution into the medication reservoir. Do not exceed the volume recommended by the manufacturer.

4. Keep the nebulizer in an upright position.

5. Place the nebulizer in the ventilator circuit at the position recommended by the manufacturer.

6. Have the patient seated in an erect or semi-erect position.*

7. Turn on the power.

8. If the treatment must be interrupted, turn off the unit to avoid waste.

9. At the completion of the treatment, disassemble and clean as recommended by the manufacturer.

10. When using a mesh nebulizer, avoid touching the mesh during cleaning because this could damage the unit.

11. Follow the manufacturer's instructions for cleaning and disinfection of the nebulizer.

* Unless there is a clinical contraindication to elevating the head of the patient.

Placement of the nebulizer in the ventilator circuit affects aerosol drug delivery during mechanical ventilation. Previous studies reported that placing the jet nebulizer farther from the ETT improves drug delivery, leading to the recommendation to place the nebulizer proximal to the humidifier, ie, close to the ventilator. ${ }^{31,37,51,66-68}$ It was believed that the continuous output from the jet nebulizer filled the inspiratory limb of the circuit between inspirations, increasing the percent of output delivered with each breath through a ventilator. Wan and colleagues ${ }^{69}$ compared 3 jet nebulization modes, ie, inspiratory intermittent, continuous, and expiratory intermittent modes, in adult and pediatric lung models with the jet nebulizer placed proximal to the humidifier. Drug delivery did not differ between the nebulization modes or between adult and pediatric settings, but the time for nebulization was longer with the inspiratory intermittent mode compared to the continuous and expiratory intermittent modes. Moreover, Moraine and coworkers ${ }^{70}$ showed that, in mechanically ventilated patients, the placement of an ultrasonic nebulizer in the ventilator circuit proximal to the humidifier had no effect on the pulmonary bioavailability of drug.

Nebulizers may be operated continuously by pressurized gas or synchronized with gas flow from the ventilator. While continuous jet nebulization is powered by pressurized gas from a 50-psi wall outlet or gas cylinder, breathsynchronized nebulization is operated by a separate line to provide driving pressure and gas flow from the ventilator. When nebulization is synchronized with inspiratory flow from the ventilator, aerosol losses during exhalation are minimized and the efficiency of drug delivery is enhanced by as much as 4 times compared to continuously operated nebulization. ${ }^{16,68}$ However, some ventilators do not provide adequate driving gas pressure, which may have an adverse influence on the particle size of the aerosol and the efficiency of drug delivery from the nebulizer. Some newer ventilators have a built-in nebulizer function that could facilitate reproducible and consistent dosing. ${ }^{63,71}$ Nebulizers could also be adapted to deliver aerosols continuously for extended periods by using a dual-channel volumetric infusion pump that mixes the drug with normal saline prior to nebulization and allows the dose to be titrated according to clinical requirements. ${ }^{72}$

Jet nebulizers are less expensive, but ultrasonic and vibrating mesh nebulizers are more efficient than jet nebulizers as they provide a higher rate of nebulization in a shorter period of time. $6,37,48,52,66,73$ The relative expense of ultrasonic and vibrating mesh nebulizers is a limiting factor for their widespread use in ventilated patients. ${ }^{74}$

\section{Soft Mist Inhaler}

An adapter designed for in-line use of the Respimat soft mist inhaler (Boehringer-Ingelheim, Germany) is not commercially available as yet. The in vitro dose delivery of tiotropium, and ipratropium bromide and albuterol in combination, was compared with pMDI delivery using different valved holding chambers and spacers during simulated mechanical ventilation. The Respimat with the prototype 
in-line adapter provided better fine-particle dose delivery than other accessory device combinations. ${ }^{75}$

\section{Dry Powder Inhalers}

Dry powder inhalers could be employed in ventilator circuits either by employing the ventilator's inspiratory air flow to generate an aerosol or by first producing an aerosol and then entraining the drug particles into the air flow from the ventilator. Everard and colleagues ${ }^{76}$ employed a modified Turbuhaler in a dry ventilator circuit and found that $\sim 20 \%$ of the nominal dose was delivered to a filter placed at the distal end of the ETT. Humidity reduces drug delivery from dry powder inhalers, ${ }^{77}$ and because ventilated patients routinely receive warm and humidified gas, the feasibility of administering dry powders during mechanical ventilation needs further evaluation.

\section{Intratracheal Nebulizing Catheter}

The intracorporeal nebulizing catheter (Aeroprobe; Trudell Medical International, London, ON, Canada), produces an aerosol in the trachea. ${ }^{78}$ Preliminary data suggest that lung deposition is improved with the use of the catheter compared to more conventional forms of aerosol administration. ${ }^{79}$ Intratracheal nebulizing catheters could be employed to target a variety of therapeutic agents and genes to the site of lung disease in ventilated patients ${ }^{80,81}$; however, the use of the intratracheal catheters is investigational at present.

\section{Choice of Aerosol Delivery Device in Mechanically Ventilated Patients}

Traditionally, pMDIs have been prescribed for out-patient treatment of airway obstruction, whereas nebulizers have been widely used during in-hospital visits. However, bronchodilator therapy with either pMDIs or nebulizers produces similar therapeutic effects in ventilator-supported patient, ${ }^{5,9,18,23,82,83}$ and when employed in an optimal manner, pMDIs and nebulizers are equally effective in the treatment of mechanically ventilated patients with obstructive lung disease. ${ }^{21,84}$ In the past, pMDIs were commonly employed for routine bronchodilator therapy because of convenience of use and decreased potential for contamination compared to jet nebulizers. ${ }^{85-88}$ In one survey of neonatal ICUs, pMDI use was reported to have increased significantly over a period of approximately 10 years. ${ }^{87} \mathrm{In}$ the majority of adult ICUs in the United States, pMDIs were reported to be preferred for routine bronchodilator therapy ${ }^{88}$ Bronchodilator administration with pMDIs was previously thought to be more cost-effective than nebulizers ${ }^{89-91}$; however, this may no longer hold true for the branded HFA-pMDIs and newer vibrating mesh nebuliz- ers are convenient and less prone to bacterial contamination than most jet nebulizers. Moreover, a 2013 Cochrane review $^{92}$ did not find sufficient evidence to recommend pMDIs versus nebulizers in mechanically ventilated subjects, but there seemed to be a trend toward achieving lower airway resistance with the nebulizer. Many ICUs in the United States now employ vibrating mesh nebulizers for bronchodilator treatments and for delivery of antibiotics, surfactant, prostaglandins, and other formulations that are not available in pMDIs. ${ }^{6,58,93}$

A self-administered electronic survey among 854 physicians who worked regularly in ICUs in 70 countries (predominantly in Europe) found that almost all employed aerosolized therapies during mechanical ventilation. ${ }^{94} \mathrm{Neb}$ ulizers were used exclusively by $43 \%$, and pMDIs were also used by $55 \%$. Among those who used nebulizers, jet nebulizers were used more often $(55 \%)$ than ultrasonic $(44 \%)$ or vibrating mesh nebulizers (14\%). As a follow up to this survey, the investigators performed a 2-week crosssectional study to assess the prevalence of aerosol therapy in 81 intensive and intermediate care units in 22 countries. ${ }^{62}$ Among subjects receiving mechanical ventilation, $22 \%$ received at least one inhaled medication over the 2 -week period. This inhaled therapy was administered by jet nebulizer (42\%), ultrasonic nebulizer (17\%), vibrating mesh nebulizer (11\%), or pMDI (29\%). Thus, inhaled drugs are commonly administered to mechanically ventilated patients via a variety of devices, but there is considerable variation among centers in the devices employed for aerosol delivery. ${ }^{62,94}$ For mechanically ventilated patients, nebulization is the most versatile and widely used method of pulmonary drug delivery, whereas pMDIs are more suited for delivery of formulations that are available in this device (eg, bronchodilators), and it is feasible to administer a dose that produces a clinical response at a reasonable cost that is comparable to or lower than the cost associated with administration of nebulizer treatments.

\section{Drugs Administered via Inhalation to Mechanically Ventilated Patients}

At the present time, a variety of drug aerosols, including bronchodilators, corticosteroids, antibiotics, prostanoids, surfactant, mucolytics, biologicals, genes, and miscellaneous other agents are administered in mechanically ventilated patients (Table 5). ${ }^{93}$ Bronchodilators are among the most commonly used drugs in the ICU.5,62,94,95 The indications for using inhaled bronchodilators in mechanically ventilated patients are shown in Table 6 .

In ventilator-supported patients with air flow obstruction, such as patients with acute asthma, exacerbations of COPD, or bronchiolitis, inhaled bronchodilators are frequently employed to reduce airway resistance. ${ }^{17-20,95}$ In patients with air flow obstruction, inhaled bronchodilators 
Table 5. Therapeutic Aerosols in Mechanically Ventilated Patients*

\begin{tabular}{|c|c|}
\hline Drugs & Delivery Device for Administration \\
\hline $\begin{array}{l}\text { Bronchodilators: albuterol, formoterol, arformoterol, fenoterol, metaproterenol, ipratropium, } \\
\text { albuterol + ipratropium }\end{array}$ & $\begin{array}{l}\text { pMDI with spacer/jet nebulizer/vibrating } \\
\text { mesh nebulizer }\end{array}$ \\
\hline \multicolumn{2}{|l|}{ Corticosteroids: } \\
\hline budesonide & Jet nebulizer \\
\hline beclomethasone, fluticasone & pMDI with spacer \\
\hline $\begin{array}{l}\text { Combination bronchodilator and corticosteroid: } \\
\text { salmeterol }+ \text { fluticasone, formoterol }+ \text { mometasone }\end{array}$ & pMDI with spacer \\
\hline \multicolumn{2}{|l|}{ Antibiotics: } \\
\hline tobramycin*, amikacin $\dagger$, amikacin + fosfomycin $\dagger$, colistin*, ciprofloxacin $\dagger$ & Jet nebulizer/vibrating mesh nebulizer \\
\hline ribavarin & Small particle aerosol generator \\
\hline amphotericin B & Jet nebulizer \\
\hline Surfactant: Exosurf $\dagger$, Survanta $\dagger$, Curosurf $\dagger$, Infasurf $\dagger, \mathrm{KL} 4 \dagger$ & Jet nebulizer/vibrating mesh nebulizer \\
\hline Mucolytics: $N$-acetylcysteine*, dornase alfa* & Jet nebulizer \\
\hline Biologicals: monoclonal antibodies $\dagger$ & Jet nebulizer/vibrating mesh nebulizer \\
\hline Genes: siRNA $\dagger$ & Jet nebulizer/vibrating mesh nebulizer \\
\hline Prostanoids: epoprostenol* ${ }^{*}$, iloprost*, treprostinil* & Vibrating mesh nebulizer \\
\hline Miscellaneous: heparin $\dagger$, morphine $\dagger$, furosemide $\dagger$ & Jet nebulizer \\
\hline $\begin{array}{l}\text { * No therapies are specifically cleared by the U.S. Food and Drug Administration for use in this clinical setting. The use o } \\
\text { use. } \\
\dagger \text { The use of these drugs and agents is investigational. } \\
\text { pMDI = pressurized metered-dose inhaler } \\
\text { siRNA }=\text { small interfering ribonucleic acid }\end{array}$ & mechanically ventilated patients represents off-label \\
\hline
\end{tabular}

Table 6. Indications for Aerosolized Bronchodilator Therapy in Mechanically Ventilated Patients

1. Severe asthma

2. $\mathrm{COPD}$

3. Acute bronchospasm or wheezing

4. Elevated airway resistance

5. Dynamic hyperinflation/intrinsic PEEP

6. Difficulty in weaning

7. Chronic ventilator dependence

improve wheezing 96 and hemodynamics, ${ }^{97}$ and they reduce airway resistance and intrinsic PEEP (PEEPi) levels. $5,17,36,97$ In addition to patients with confirmed expiratory air flow obstruction, expiratory flow was also shown to improve after bronchodilator administration in a heterogeneous group of ventilated patients. ${ }^{98}$ In patients with ARDS, elevated levels of airway resistance were reduced with nebulized metaproterenol.99,100 Bronchodilators also reduce the work of breathing. ${ }^{101}$ They also could reduce the sensation of dyspnea while improving patient-ventilator interaction, and they could facilitate weaning in patients with limited cardiopulmonary reserve. ${ }^{101}$ Combining $\beta$-2 adrenergic and anti-cholinergic bronchodilators has a greater effect than therapy with either agent alone. ${ }^{102} \beta$-agonists could also enhance mucociliary clearance ${ }^{103}$ and accelerate the resolution of alveolar edema in patients with acute lung injury or ARDS. ${ }^{104}$ However, a multi-center trial was stopped early after interim analysis showed that administration of nebulized albuterol ( $5 \mathrm{mg}$ every $4 \mathrm{~h}$ for up to $10 \mathrm{~d}$ ) did not improve ventilator-free days or mortality rates before hospital discharge. ${ }^{105}$ Thus, a wide spectrum of ventilator-supported patients receive bronchodilators, and this contributes to additional cost of treatment. ${ }^{88}$ However, it is unclear whether regular administration of bronchodilators to such a diverse group of patients, besides those with exacerbations of asthma or COPD, confers any benefit in terms of improved clinical outcomes, ${ }^{105}$ such as the duration of mechanical ventilation, length of ICU stay, length of hospital stay, in-hospital mortality, or long-term mortality. Moreover, higher doses of $\beta$-agonists have the potential to cause hypokalemia and cardiac arrhythmias. ${ }^{19,106-108}$ Unfortunately, no randomized, controlled trials have been performed to evaluate the effect of bronchodilator therapy on clinically relevant outcomes in ventilator-supported patients. ${ }^{21,88,109}$ Moreover, variations in the method of administration and assessment of response make it difficult to compare the results of various studies. $^{21}$

There is growing usage of inhaled antibiotics, especially inhaled aminoglycosides and inhaled colistin, for treatment of ventilator-associated pneumonia (VAP) with drugresistant Gram-negative organisms. For pulmonary delivery of antibiotics, efficient nebulization systems are essential both to attain sufficient therapeutic efficacy, and to keep the time needed for administration of the total dose within acceptable limits (15-30 min). ${ }^{73,110}$ Recent advances 
in nebulizer technology, namely the development of vibrating mesh nebulizers with breath coordination, have enabled significant improvements in the efficiency of antibiotic delivery. ${ }^{46,64,111}$ Guidelines for treatment of hospital-acquired pneumonia and VAP acknowledge methodological limitations in previous studies of inhaled antibiotics and give a weak recommendation for use of inhaled antibiotics as adjunctive therapy for treatment of pneumonia due to organisms that are susceptible only to aminoglycosides or colistin or as adjunctive rescue therapy for patients who are not responding to systemic antimicrobial therapy. ${ }^{12}$ A systematic review of studies that predominantly employed jet nebulizers for antibiotic delivery concluded that emergent resistance decreased with inhaled antibiotics in subjects with ventilator-associated tracheobronchitis and VAP caused by susceptible organisms. Subjects with VAP due to resistant organisms had higher clinical resolution, but ventilator duration or mortality did not improve. ${ }^{113}$ A multi-center, randomized, double-blind, placebo-controlled, parallel group phase 2 study compared amikacin (300 $\mathrm{mg}$ base) and fosfomycin $(120 \mathrm{mg}$ ) that was $\mathrm{pH}$ and osmolality adjusted via a vibrating mesh nebulizer placed proximal to the Y-connector and run continuously in a humidified circuit. ${ }^{114}$ The Clinical Pulmonary Infection Score, mortality and clinical cure at day 14 , and mortality and ventilator-free days did not differ between the treatment and placebo group. Similar to the findings of the systematic review, ${ }^{113}$ patients with pneumonia due to panresistant Acinetobacter showed a trend for more ventilator-free days and higher clinical cure rates in subjects treated with amikacin and fosfomycin that was $\mathrm{pH}$ and osmolality adjusted. ${ }^{114}$ Two multi-center, prospective, randomized, double-blind, placebo-controlled phase 3 studies using an investigational inhaled amikacin solution administered with the PDDS Clinical (NCT 01799993) are expected to complete enrolment this year. At present, the recommendation is to employ inhaled antibiotics as adjunctive therapy for treatment of ventilator-associated tracheobronchitis or VAP due to Gram-negative organisms that are resistant to multiple drugs. ${ }^{112}$

In critically ill patients, refractory hypoxemia and pulmonary hypertension present challenging management problems, and they also influence morbidity and mortality. ${ }^{115}$ Inhaled vasodilators decrease pulmonary vascular resistance and right ventricular afterload with improvement in right heart function, ventilator perfusion mismatch and arterial oxygenation. Systemic side effects, such as hypotension, which occur with intravenous vasodilators, are minimized by using the inhaled route of administration. Inhaled nitric oxide (INO) has been employed for many years, and although it is only approved for treatment of hypoxic respiratory failure associated with clinical or echocardiographic evidence of pulmonary hypertension in neonates ( $>34$ weeks gestation), ${ }^{116}$ its use has expanded into a variety of off-label uses as a rescue therapy for acute hypoxic respiratory failure with or without pulmonary hypertension and right heart failure. ${ }^{116}$ However, INO is very expensive and has a risk of severe rebound hypertension if therapy is abruptly discontinued for any reason.

Continuous intravenous infusions of prostaglandin $\mathrm{I}_{2}$ (epoprostenol) or prostaglandin $\mathrm{E}_{1}$ (alprostadil) have been employed in patients with ARDS to improve intra-pulmonary shunting and severe hypoxemia. The anti-inflammatory and anti-platelet aggregation properties of these agents may have additional potential benefits in patients with ARDS. ${ }^{117}$ After intravenous administration of epoprostenol to patients with ARDS, pulmonary artery pressures and cardiac output improved, but there was also increased venous admixture and systemic hypotension. ${ }^{118,119}$ In contrast, inhalation of prostaglandins reduces pulmonary artery pressure and enhances blood flow to well-ventilated but poorly perfused lung regions, leading to better ventilation perfusion matching and improved oxygenation. ${ }^{120,121}$ In addition to epoprostenol and alprostadil, prostacylin analogs, such as iloprost and treprostinil, are also available for inhalation. These agents produce selective pulmonary vasodilation at lower doses, and higher doses could lead to bronchospasm and systemic side effects. While epoprostenol and alprostadil have to be nebulized continuously, iloprost and treprostinil could be given intermittently because of their longer plasma half-lives. However, critically ill patients may require administration every 2 hours, and the precise dosing regimen for these agents in mechanically ventilated patients have not been determined.

In mechanically ventilated patients with ARDS, inhaled epoprostenol and alprostadil are as effective as INO in improving oxygenation and hemodynamics, ${ }^{122-124}$ although the preponderance of evidence is based on observational studies and the doses of inhaled vasodilators employed, duration of therapy, and the time at which therapy was initiated have been variable. ${ }^{125}$ One randomized, controlled trial that compared alprostadil to placebo reported that oxygenation improved after a brief exposure to inhaled alprostadil, but the change in mean $\mathrm{P}_{\mathrm{aO}_{2}} / \mathrm{F}_{\mathrm{IO}_{2}}$ ratio with alprostadil was not significantly different from the change with placebo. ${ }^{126}$ A retrospective, noninterventional, propensity-matched, noninferiority cohort study in subjects with ARDS found that the median ventilator-free days from day 1 to day 28 , was $3.73 \mathrm{~d}$ with inhaled epoprostenol and $1.56 \mathrm{~d}$ with INO, with a mean difference of $2.16 \mathrm{~d}(95 \% \mathrm{CI}-0.61-4.9 \mathrm{~d})$. $^{127}$ Thus, inhaled epoprostenol was shown to be noninferior to INO. In summary, inhaled prostaglandins are employed in patients with ARDS to treat refractory hypoxemia and pulmonary hypertension as less expensive alternatives to INO, but further studies are needed to determine optimal methods of administering inhaled prostaglandins and their effect on clinical outcomes in mechanically ventilated patients. The 


\section{Aerosol Delivery During Invasive Mechanical Ventilation}

use of all inhaled prostaglandins for mechanically ventilated adult patients with ARDS is currently off-label.

While aerosolized therapies are now routinely and effectively employed in mechanically ventilated patients, these therapies are often randomly used and there is little consistency in their use between different ICUs and various centers. ${ }^{62,94}$ The purpose of this article is to attempt to define the goals of aerosol therapy in mechanical ventilation so that therapies are applied more consistently and rationally while also employing the optimal techniques of administration.

\section{Goal-Directed Aerosol Therapy in Mechanically Ventilated Patients}

The overall goal of aerosolized therapy is to provide maximum benefit to the patient while minimizing adverse effects. These goals could be conceptualized as shown in Table 7.

\section{Assure Drug Delivery}

The path from the point of generation of the aerosol droplets to the lung must remain clear of any impediments. This path includes the ventilator circuit, the right-angled swivel connector, the in-line suction catheter, the heatand-moisture exchanger (HME) filter, the artificial airway, and narrowing in the upper airway. Another factor that could reduce the delivery of drug particles to the lung is washout of the aerosol by continuous air flow in the circuit. Moreover, the presence of humidity in the circuit plays a very important role in reducing the efficiency of drug delivery in patients receiving mechanical ventilation..$^{9,23}$

Type of Artificial Airway. The placement of an artificial airway with a cuffed tube allowing application of positive pressure, preventing aspiration, and facilitating suctioning to maintain airway patency is important for delivery of high concentrations of oxygen. However, the artificial airway is the narrowest portion of the ventilator circuit and the site of the highest resistance to air flow. The narrower diameter of the artificial airway compared to the normal airway coupled with high inspiratory air flows employed during mechanical ventilation predispose the system to air flow turbulence and higher particulate losses due to impaction. ${ }^{128}$ Aerosol impaction on the ETT poses a significant barrier to effective drug delivery in infant and pediatric mechanical ventilation (ETT inner diameter 3-6 mm), ${ }^{129,130}$ with aerosol delivery efficiency being lower with narrower ETTs. ${ }^{131}$ In adult mechanical ventilation, there was no difference in nebulizer efficiency with ETTs with inner diameters of $7 \mathrm{~mm}$ versus $9 \mathrm{~mm} .{ }^{67}$ Drug losses within the ETT could be minimized by placing the
Table 7. Goals of Aerosol Therapy in Mechanically Ventilated Patients

\begin{tabular}{|c|c|}
\hline Goals & Factors to Consider \\
\hline $\begin{array}{l}\text { Assure drug delivery to the } \\
\text { lower respiratory tract }\end{array}$ & $\begin{array}{l}\text { Ventilator circuit blockage } \\
\text { Endotracheal tube size } \\
\text { Circuit humidity } \\
\text { Heat and moisture exchanger } \\
\text { Inhaled gas density } \\
\text { Right angled adapter } \\
\text { In-line suction catheter } \\
\text { Continuous bias flow } \\
\text { Obstruction in major airways }\end{array}$ \\
\hline $\begin{array}{l}\text { Optimize drug deposition } \\
\text { in the lung }\end{array}$ & $\begin{array}{l}\text { Use of a chamber spacer } \\
\text { Position in the circuit } \\
\text { Position of the patient } \\
\text { Ventilatory parameters }\end{array}$ \\
\hline Provide a consistent dose & $\begin{array}{l}\text { Aerosol particle size } \\
\text { Synchronization } \\
\text { Suctioning } \\
\text { Avoid treatment interruption } \\
\text { Inter-device variability } \\
\text { Inter-provider variability }\end{array}$ \\
\hline $\begin{array}{l}\text { Avoid inappropriate } \\
\text { therapies }\end{array}$ & $\begin{array}{l}\text { Inhaled corticosteroids } \\
\mathrm{N} \text {-acetylcysteine } \\
\text { Dornase alfa } \\
\text { Inhaled } \beta \text {-agonists } \\
\text { IV antibiotic formulations } \\
\text { Drug combinations }\end{array}$ \\
\hline $\begin{array}{l}\text { Assure reproducibility } \\
\text { across clinical settings }\end{array}$ & $\begin{array}{l}\text { Age } \\
\text { Morbid obesity } \\
\text { Various disease settings } \\
\text { Various ventilator modes }\end{array}$ \\
\hline $\begin{array}{l}\text { Employ clinically feasible } \\
\text { methods }\end{array}$ & $\begin{array}{l}\text { Use of intratracheal catheters } \\
\text { Manual resuscitation bag delivery }\end{array}$ \\
\hline $\begin{array}{l}\text { Ensure that therapies are } \\
\text { safe for patients, } \\
\text { caregivers, and the } \\
\text { environment }\end{array}$ & $\begin{array}{l}\text { Ventilator settings } \\
\text { Device cleaning } \\
\text { Frequent disconnection } \\
\text { Additional nebulizer airflow } \\
\text { Expiratory filter replacement } \\
\text { Higher drug doses } \\
\text { Humidification off } \\
\text { Cough and spread of infection } \\
\text { Antibiotics and resistance } \\
\text { Genetic material and chemotherapy }\end{array}$ \\
\hline $\begin{array}{l}\text { Employ therapies that have } \\
\text { reasonable cost }\end{array}$ & $\begin{array}{l}\text { Depends on therapy and clinical indication } \\
\text { Comparative cost } \\
\text { Effect on clinical outcomes }\end{array}$ \\
\hline
\end{tabular}

aerosol generator at a distance from the ETT instead of being directly connected to it. ${ }^{128}$ A greater proportion of the aerosol is lost in the ETT when the circuit is humidified compared to a dry circuit, and this difference contributes to the reduced efficiency of drug delivery in humidified circuits. ${ }^{11}$ In vitro studies have shown minimal drug deposition within ETTs with jet nebulizers; however, significant ETT deposition of aerosol occurs with ultrasonic nebulizers. ${ }^{48}$

Aerosol deposition in tracheostomy tubes has not been studied in as much detail as with ETTs. By using a mass 
balance technique, O'Riordan and colleagues ${ }^{13}$ found that approximately $10 \%$ of the nominal dose from a nebulizer deposited in the tracheostomy tube of mechanically ventilated subjects. The majority of aerosol deposition $(\sim 7 \%)$ occurred during exhalation, and $<3 \%$ was deposited in the tube during inhalation. Because in vitro studies are unable to directly determine aerosol deposition during exhalation, such studies could significantly underestimate the actual deposition of aerosol in the artificial airway. Ari and co-workers ${ }^{132}$ found in a bench model of mechanical ventilation that a greater percentage of the dose was delivered via a tracheostomy tube compared to an ETT with either jet nebulizer or pMDI. Piccuito and Hess ${ }^{133}$ reported that drug delivery through a tracheostomy tube in a bench model of mechanical ventilation was influenced by the delivery device (nebulizer or pMDI), bias gas flow, and the patient interface. Specifically, these investigators reported that, in spontaneously breathing patients with a tracheostomy, the use of a nebulizer without additional gas flow and a T-piece adapter resulted in a 3-fold higher drug delivery compared to high flow through the circuit (30 L/min) and connection of the nebulizer to a tracheostomy mask. ${ }^{133}$ Another in vitro study found that removing the inner cannula of the tracheostomy tube prior to aerosol administration increased drug delivery. ${ }^{134}$ With in vitro and in vivo models ( 3 of the 6 subjects had tracheostomies), Miller and co-workers demonstrated that breathactuated nebulization and humidity were the most important factors influencing aerosol delivery during mechanical ventilation. ${ }^{16}$ In contrast, one group of investigators who compared pulmonary deposition of ${ }^{99 \mathrm{~m}} \mathrm{Tc}$-labeled fenoterol administered by pMDI and spacer to mechanically ventilated patients found no difference in aerosol delivery between tracheostomy and ETTs $(6.1 \% \pm 2.8 \%$ vs $4.6 \% \pm 3.0 \%$, respectively; $P<.12) .135$

Heat and Humidity. Bench models of mechanical ventilation have consistently demonstrated a reduction of up to 40 $-50 \%$ in heated and humidified ventilator circuits compared to dry circuits at room temperature. ${ }^{10,11,30,66,136,137}$ While higher deposition with delivery of cold dry gas might seem attractive to deliver more drug to the lung, the increased efficiency of aerosol delivery must be weighed against the potential damage to the respiratory mucosa from prolonged ventilation with cold dry gas. ${ }^{9}$ Active heated humidifiers are commonly used during mechanical ventilation of infants and small children, and a substantial proportion of adults. The heat and humidity of an inhaled gas to body-temperatureand-pressure-saturated conditions promotes more normal mucociliary clearance, prevents drying of the airway mucosa, and reduces bronchospastic responses to breathing cold dry air. The heated humidity in the ventilator circuit is associated with increases in aerosol particle size during mechanical ventilation. ${ }^{10,11,30,66,136,137}$ When a pMDI is used in a ventilator circuit, humidity probably interferes with propellant evaporation so that drug particles remain of a larger size and impaction losses are increased. ${ }^{9}{ }^{138}$ Even though humidity has an unwanted effect on drug delivery, removing the humidifier is not recommended for routine aerosol therapy as it requires breaking the circuit and waiting several minutes for the circuit to dry. Even then, as shown by Lin and colleagues, such interventions may not improve aerosol delivery. ${ }^{139}$ These investigators reported that delivery efficiency of albuterol from a pMDI with a spacer chamber during mechanical ventilation with a heated wire circuit was not reduced for more than $1 \mathrm{~h}$ after turning on the heated humidifier. Reduction of aerosol delivery occurred as substantial condensation formed in the spacer and tubing, with reductions to levels previously reported with a humidified ventilator circuit. After $3 \mathrm{~h}$ of humidifier operation, turning off the humidifier for up to $30 \mathrm{~min}$ prior to administration of aerosol via pMDI did not improve drug delivery. ${ }^{139}$ The authors suggested that the presence of water condensate in the circuit and chamber was sufficient to achieve a high enough absolute humidity that continued to reduce efficiency of inhaled drug delivery even after the humidifier was turned off. 139

For inexpensive drugs, such as salbutamol or ipratropium bromide, increasing the dose may be safer than turning off the humidifier. For more expensive drugs, such as antibiotics, the potential efficiency advantage of a dry ventilator circuit may be cost-effective. If a dry ventilator circuit needs to be used for aerosol delivery, the ventilator should be used with an HME, and the administration of medication should be achieved in a short period $(<10 \mathrm{~min})$ to minimize the effects of dry gas on the airway mucosa. ${ }^{83}$

HMEs are utilized as an alternative to heated humidifiers. ${ }^{140}$ The filter in the HME captures the heat and moisture in the exhaled breath and transfers part of it to the air in the following inspiration, providing about $70 \%$ absolute humidity at $30^{\circ} \mathrm{C}$. The HME filter captures drug particles in the aerosol and markedly reduces the efficiency of drug delivery. Therefore, the HME must be removed from the circuit during aerosol treatments or the pMDI should be placed between the HME and ETT. While placement of a pMDI between the HME and ETT could provide adequate drug delivery, with a nebulizer placed distal to the HME, backflow of aerosol could deposit on the HME filter and increase its air flow resistance, thus increasing the work of breathing for the patient. ${ }^{141}$ Some manufacturers have introduced HMEs that accommodate aerosol delivery. In these HMEs, the inspiratory gas flow bypasses the filter in the HME during aerosol delivery so that is possible to achieve adequate aerosol delivery without removing the HME from the circuit. ${ }^{142}$

Density of Inhaled Gas. The density of the inhaled gas also influences drug delivery during mechanical ventilation. High inspiratory flows employed during mechanical 
ventilation are associated with turbulence. Inhalation of a less dense gas, such as a 70:30 helium-oxygen (heliox) mixture, makes air flow less turbulent and more laminar, which may improve aerosol deposition by decreasing particle-impaction losses caused by air flow turbulence. ${ }^{143}$ The use of heliox mixtures improved drug delivery in a pediatric model of mechanical ventilation. ${ }^{144}$ In a bench model of adult mechanical ventilation, drug delivery from a pMDI was noted to be $50 \%$ higher with a $80: 20$ heliox mixture than with oxygen alone. ${ }^{145}$ In contrast, nebulizer operation with heliox reduced drug output and respirable mass. ${ }^{145,146}$ A preferred strategy in maximizing aerosol deposition with a nebulizer is to power it at $6-8 \mathrm{~L} / \mathrm{min}$ with oxygen and entrain the aerosol into a ventilator circuit that contains heliox. ${ }^{145}$ Aerosol deposition to the lower airways is increased by $50 \%$ with that technique compared to using oxygen by itself in the ventilator circuit. ${ }^{145}$ It is important to remember that heliox may adversely affect the function of some ventilators and therefore the system must be tested before use to prevent detrimental effects on patients. ${ }^{147,148}$

Heliox has been used in clinical practice for many decades; however, its role in treatment of patients with severe asthma, exacerbations of COPD, or bronchiolitis has provided mixed results. ${ }^{149,150}$ Moreover, treatment with heliox is costly and technically complex, and its role in treatment of mechanically ventilated patients has not been established. ${ }^{151}$

Obstruction in the Ventilator Circuit. Any obstruction in the ventilator circuit or ETT, whether due to accumulation of water, bends, or kinks, could lead to greater aerosol impaction at the site of narrowing. The exit angle at the opening of the airway also affects the aerosol flow properties and the potential for particle impaction. Mucus plugs blocking the artificial airway should be effectively suctioned before administering aerosols. After the tube is placed inside the airway, there is build-up of an alginate, polysaccharide matrix known as a biofilm. ${ }^{152}$ The narrowing and roughening of the inner surface of the artificial airway produced by these biofilms could have an additive effect on aerosol losses.

Bias Flow. With flow-triggering, a bias flow through the ventilator circuit helps reduce the patient's work of breathing. The presence of a bias flow increases the transport of aerosol from the aerosol generator and increases the washout of aerosol from the circuit during exhalation when a continuously operating nebulizer is used for aerosol delivery, but it does not have a similar influence on drug delivery from pMDIs. ${ }^{10}$ Ari and colleagues ${ }^{66}$ studied the influence of bias flow with a jet and vibrating mesh nebulizer on albuterol delivery in a model of adult mechanical ventilation. They reported that increasing bias flows through the ventilator circuit decreased the amount of aerosol deposited and lower bias flows ( $\leq 2 \mathrm{~L} / \mathrm{min}$ ) are recommended for greater aerosol delivery with nebulizers that operate continuously. ${ }^{66}$ The impact of the bias flow is greater for jet nebulizers than for vibrating mesh nebulizers because the clearance of aerosol from the ventilator circuit is increased by the bias flow in addition to the continuous flow from the jet nebulizer.

Swivel Connector/In-line Suction Catheters. Significant aerosol losses occur at the connection between the Y-piece and ETT. ${ }^{11}$ Larger drug particles in the aerosol have difficulty in negotiating the right-angled bend of the swivel connector. A streamlining approach that eliminates sudden changes in the diameter of the ventilator circuit components and applies a smooth curvature to changes in the path of the aerosols is a proposed alternative that could lead to improved efficiency of aerosol delivery. ${ }^{153}$ Likewise, some in-line suction catheters could impede aerosol delivery. Manthous and colleagues found a significantly greater effect of nebulized albuterol on airway resistance in 3 mechanically ventilated patients when they connected the Y-piece directly to the ETT compared to the effect observed with an in-line suction catheter and connector in place. ${ }^{154}$

Obstruction in Major Airways. Obstruction in the trachea and major bronchi distal to the artificial airway, produced by tumors, stenosis, tracheomalacia, stricture, edema, or granulation tissue, could adversely affect aerosol delivery to the lower airways. Tracheal stenosis may have a greater impact on deposition of larger drug particles $(10 \mu \mathrm{m})$ than smaller drug particles $(2.5 \mu \mathrm{m}) .{ }^{155} \mathrm{In}$ such clinical situations, heliox could be used as an adjunctive therapy to reduce airway resistance ${ }^{156}$ and improve delivery of aerosols beyond the area of critical obstruction.

\section{Optimize Drug Deposition in the Lung}

Drug deposition in the lung must be optimized to achieve the desired clinical effects. ${ }^{23}$ The ventilatory parameters and the position of the patient could determine the deposition of drug in the lower respiratory tract during mechanical ventilation.

Ventilator-Related Factors. The characteristics of the ventilator breath have an important influence on aerosol drug delivery. A tidal volume of $500 \mathrm{~mL}$ or more (in an adult), ${ }^{10}$ longer inspiratory time, and slower inspiratory flows improve aerosol delivery. ${ }^{10}$ An inspiratory flow of $30-50 \mathrm{~L} / \mathrm{min}$ is optimal for aerosol delivery; however, slow inspiratory flows may increase inspiratory time and, by reducing the time for exhalation, may have the unintended consequence of increasing PEEPi. ${ }^{148}$ 
Drug delivery is linearly correlated with a longer duty cycle (inspiratory time/total breath duration) for both pMDIs and nebulizers. ${ }^{10,11,67}$ Moreover, drug delivery is improved when a pMDI is synchronized with a simulated spontaneous breath compared with a controlled ventilator breath of similar tidal volume. ${ }^{10}$

The inspiratory waveform influences drug delivery from nebulizers, but it has much less influence on drug delivery from a pMDI. ${ }^{157}$ Unlike pMDIs, nebulizer efficiency could be different during pressure-controlled ventilation than during volume-controlled ventilation. The use of a spacer with a pMDI improves the efficacy of bronchodilator therapy in ventilator-supported patients. The best results are obtained when the pMDI actuation is synchronized with the onset of inspiration. ${ }^{5,28}$

In mechanically ventilated patients with COPD, the application of external PEEP at a level that counterbalances PEEPi enhances the bronchodilator effect of albuterol. ${ }^{97}$ The additive effects of external PEEP and albuterol could be explained by the effect of albuterol in reducing timeconstant inequality, thereby producing alveolar recruitment during tidal ventilation, and the application of external PEEP maintains this alveolar recruitment. The net effect is that the level of PEEPi is markedly reduced by the combination of albuterol and external PEEP. ${ }^{97}$ In contrast, Guérin and colleagues reported that after administration of nebulized fenoterol, respiratory mechanics improved when PEEP was set at zero. ${ }^{158}$ Increasing the PEEP level to $85 \%$ of the PEEPi level did not enhance the bronchodilator response. ${ }^{158}$ With careful attention to the technique of administration, a bronchodilator response can be expected in most mechanically ventilated patients with asthma or COPD. However, most mechanically ventilated patients do not show incremental effects with higher drug doses. ${ }^{17}$

Patient Position. Spontaneously breathing patients usually adopt a sitting or standing posture during aerosol inhalation. In contrast, most patients are recumbent or semirecumbent while receiving mechanical ventilation and inhaled drug therapy. Ventilator-dependent patients should preferably sit in bed or in a chair during inhalation therapy. In patients with exacerbations of COPD, administration of bronchodilator aerosols to semi-recumbent patients produced a significant response. $5,17-19,20,22,36,82$ A semi-recumbent position, with the head end of the bed elevated to $20-30^{\circ}$ above horizontal, should suffice for ventilatorsupported patients who are unable to sit upright during aerosol administration.

Use Appropriate Methods to Assess the Response. The response to bronchodilators depends on several variables: patient airway geometry, degree of airway responsiveness, severity of disease, quantity and type of secretions, and counter-regulatory effects of airway inflammation and other drugs. Most investigators assess response by measuring inspiratory airway resistance. Airway resistance in ventilated patients is commonly measured by performing rapid airway occlusions at constant flow inflation. ${ }^{159}$ This technique involves performing a breath-hold at end-inspiration by occluding the expiratory port. Total or maximal inspiratory resistance can be partitioned into minimal inspiratory resistance, which reflects ohmic resistance of the airways, and additional effective resistance (ie, the difference between maximal and minimal inspiratory resistance). ${ }^{159}$ Similarly, airway occlusion at end-expiration produces an increase in airway pressure to a plateau value, signifying PEEPi. ${ }^{36}$

Most ventilated patients with COPD demonstrate a decrease in airway resistance and PEEPi after bronchodilator administration. That the difference between maximal and minimal inspiratory resistance does not decrease significantly after albuterol delivery with a pMDI ${ }^{17,36}$ suggests that the bronchodilator effect occurs predominantly in the central airways with little effect on viscoelastic behavior or time-constant inhomogeneities in the lung. Moreover, albuterol does not significantly influence the elastic properties of the lung. ${ }^{36}$ In contrast, a greater decline in the difference between maximal and minimal inspiratory resistance was noted after nebulizer delivery of fenoterol and ipratropium bromid. ${ }^{82}$ This difference in response between pMDIs and nebulizers could be explained by higher drug deposition in peripheral airways with a nebulizer.

Kondili and colleagues measured expiratory resistance of the respiratory system in mechanically ventilated patients with COPD exacerbations. ${ }^{160}$ They found that albuterol significantly reduced expiratory inspiratory resistance and enhanced the rate of lung emptying to the end of expiration. Interestingly, these investigators did not find any correlation between changes in expiratory inspiratory resistance and changes in end-inspiratory resistance after albuterol administration. ${ }^{160}$ This discrepancy could be attributed to additional contributions by flow limitation and airway narrowing during expiration to the total expiratory resistance.

Pressure, flow, and volume waveforms, flow-volume loops, and pressure-volume loops are continuously displayed on most modern ventilators. In mechanically ventilated patients with airway obstruction, assessment of these waveforms at the bedside aid in recognizing abnormalities in function, in optimizing ventilator settings to promote patient-ventilator interaction, and in diagnosing complications before the development of overt clinical signs. ${ }^{161}$ Pressure, flow, and volume waveforms are helpful in detecting the presence of dynamic hyperinflation. The persistence of flow at the end of relaxed expiration indicates that the system is above passive functional residual capacity and that flow is being driven by positive elastic recoil of the respiratory system at end-expiration, signifying the 
presence of PEEPi. ${ }^{161}$ Comparison of flow volume curves and flow-time curves obtained before and after drug administration could be used to assess improvements in peak expiratory flow and reduction in PEEPi with bronchodilators. ${ }^{161}$

The clinical end points for inhaled antibiotics and other inhalation therapies have been investigated. It is unclear if microbiological cure or clinical cure should be the goal of treatment in mechanically ventilated patients. Use of inhaled antibiotics as adjunctive treatment makes it difficult to show superior efficacy, especially in the presence of infection caused by organisms that are susceptible to the antibiotics that the patient is already receiving. ${ }^{114}$ Alternative study designs and end points have been suggested to determine the efficacy and safety of inhaled antibiotic therapy. ${ }^{162}$ Inhalation of pulmonary surfactant in mechanically ventilated patients with ARDS did not produce improvement in clinical outcomes. ${ }^{163,164}$ Likewise, inhaled prostaglandins are employed in patients with ARDS to treat refractory hypoxemia and pulmonary hypertension, but their effect on clinical outcomes in mechanically ventilated patients has not been established. ${ }^{125}$

\section{Provide Consistent Dosing}

Particle Size. During mechanical ventilation, larger particles are trapped in the ventilator circuit and ETT. To optimize drug delivery, devices that produce aerosols with mass median aerodynamic diameter $<2 \mu \mathrm{m}$ are more efficient during mechanical ventilation than devices that produce aerosols with larger particles. ${ }^{9,13,130}$ Nebulizers and pMDIs delivered an equivalent mass of aerosol beyond the ETT in a ventilator model. ${ }^{30}$ While nebulizers that produce aerosols with smaller particle sizes have been employed during mechanical ventilation, they require a considerably greater time to deliver a standard dose. ${ }^{13,16,56,64}$ Vibrating mesh nebulizers produce aerosols with variable particle sizes, but a significant proportion of the aerosol generated is in particles $<3.3 \mu \mathrm{m}$ in size (the fine-particle fraction). ${ }^{55-57}$

\section{Synchronizing Aerosol Generation with Inspiratory Air}

Flow. The timing of pMDI actuation in relationship to the ventilatory pattern of the patient has a large impact on delivered dose of medication. Actuation of a pMDI should be synchronized with the precise onset of inspiration to maximize aerosol drug delivery. According to Diot and co-workers, ${ }^{30}$ failure to synchronize actuations with inspiration reduces inhaled drug mass by $35 \%$. When a pMDI is actuated into a cylindrical spacer synchronized with inspiration, its efficiency increases approximately 30\% when compared to actuation during expiration. ${ }^{30}$ Likewise, nebulizers could be synchronized to generate aerosol during inspiratory air flow from the ventilator. ${ }^{13,64}$ During intermittent operation, the nebulizer generates aerosol only during the inspiratory phase, and the ventilator compensates for the flow to the nebulizer to maintain a constant tidal volume and minute ventilation..$^{5,83}$ Obviously, intermittent operation is more efficient for aerosol delivery than continuous aerosol generation. ${ }^{13,66}$

Avoid Interruption. Inhalation therapy with pMDIs only requires a few minutes to administer. However, it may require 10-15 min to administer treatments with a jet nebulizer, and treatments may have to be interrupted for other interventions in critically ill patients. The likelihood of treatment interruption is greater with longer therapy duration. The median time for nebulization with jet nebulizers (GaleMed, Taipei, Taiwan) operated in the inspiratory intermittent mode provided via a Galileo Gold ventilator (Hamilton Medical) was almost 40 min. ${ }^{69}$ Antibiotic delivery with the PDDS Clinical device may require administration for a similar duration. ${ }^{64}$ There is a distinct possibility of interruption of treatment with such a long nebulizer duration, and alarms should be incorporated to alert caregivers that the treatment has been stopped. Alternatively, continuous or expiratory intermittent modes of nebulization may be considered to reduce the duration of nebulizer treatment. ${ }^{69}$

Inter-device Variability. Nebulizer operation during mechanical ventilation could have widely variable efficiency for aerosol delivery unless careful attention is given to a number of factors that influence nebulizer performance. Miller and colleagues ${ }^{16}$ found up to 16 -fold variation in antibiotic levels in sputum after delivery with a jet nebulizer. Accounting for circuit humidity and breath-actuated nebulization could reconcile most of the observed differences. ${ }^{16}$

Inter-provider Variability. In spontaneously breathing patients, most patients are taught to self-administer their inhaled medications, whereas mechanically ventilated patients rely on clinicians or care providers to administer inhaled drugs. Clinically, it is common to observe substantial variation in the actual practice of aerosol administration between various practitioners. Drug deposition in the lung could be markedly reduced by relatively minor changes in the technique of administration. ${ }^{5,19,154}$ When optimal techniques of administration are employed, adequate drug deposition is achieved in the lung and a significant response is observed.

\section{Avoid Inappropriate Therapies}

Mucoactive Agents. The retention of airway secretions could predispose mechanically ventilated patients to development of pneumonia. Mechanical suctioning, the 
current method to clear secretions in mechanically ventilated patients, is painful and could lead to tracheal injury. Acetylcysteine (Mucomyst) is often used to enhance secretion clearance by reducing sputum viscosity. However, reports of increase in inspiratory airway resistance after administration of mucolytic agents by aerosol ${ }^{165}$ or after bolus instillation ${ }^{166}$ could pose a problem with the routine use of these agents. Recombinant human DNase (Pulmozyme, Genentech, San Francisco, California) was shown to improve mucus clearance in ventilator-supported patients with spinal cord injury and recurrent atelectasis refractory to conventional treatment. ${ }^{167}$ Pulmozyme cannot be recommended for routine use in the management of ventilator-dependent patients with inspissated secretions or mucus plugs because of cost constraints. A systematic review with meta-analysis found only 2 trials comparing nebulized dornase alfa with placebo, no therapy, or hypertonic saline. ${ }^{168}$ The evidence was of low quality and did not report any benefit or harm from use of nebulized dornase alfa in critically ill patients. Mucoactive agents may have a role in preventing lung collapse and hypoxemia in ventilated patients with thick inspissated secretions who are refractory to other forms of treatment. At the time of this review, there is not enough evidence to support the use of inhaled mucoactive agents in the management of mechanically ventilated patients, and further investigations are needed.

Inhaled Corticosteroids. In mechanically ventilated patients, the role of inhaled corticosteroids (ICS) has not been determined. In patients receiving long-term ventilation for severe COPD, Nava and Compagnoni observed a small but statistically significant reduction in airway resistance with fluticasone. ${ }^{169}$ A combination of salmeterol and fluticasone administered to mechanically ventilated patients by pMDI ( 4 doses) reportedly reduced inspiratory resistance, ${ }^{170}$ but this effect was probably because of the salmeterol component in the combination. Despite the lack of studies showing efficacy of ICS in the setting of mechanical ventilation, the majority of respondents reported employing inhaled budesonide or methylprednisolone in international surveys. ${ }^{62,94}$ In addition, many patients, especially those with exacerbations of asthma or COPD, receive high doses of systemic steroids, either parenterally or enterally. The additional benefit, if any, from a comparatively much smaller dose of ICS (eg, $1 \mathrm{mg}$ of inhaled budesonide vs $240 \mathrm{mg}$ of methylprednisolone intravenously or $60 \mathrm{mg}$ of prednisone orally) is unlikely to be significant. There is also an increased risk of pneumonia with ICS in patients with COPD. ${ }^{171,172}$ COPD is a known risk factor for developing pneumonia in mechanically ventilated patients, ${ }^{173}$ and there is a potential for further enhancing the risk of pneumonia with ICS. Furthermore, considerable costs could accrue from use of ICS, especially in combi- nation with a long-acting $\beta$-agonist. For the reasons mentioned above, the benefits of ICS in mechanically ventilated patients with COPD are unclear, and their use is not evidence-based. In hypoxemic subjects at risk of developing ARDS, early intervention with inhaled formoterol and budesonide combination was shown to lead to more rapid improvement in oxygenation. ${ }^{174}$ In this study, a higher proportion of subjects in the placebo group were in shock at baseline, and the reported differences in need for mechanical ventilation and frequency of ARDS that favored the treatment group were no longer observed after correction for baseline shock. ${ }^{174}$ Thus, there is no conclusive benefit of using ICS, and further investigations are needed to determine the appropriate dosing regimen and the risks and benefits of using ICS or ICS and long-acting $\beta$-agonist in mechanically ventilated patients.

Inhaled $\boldsymbol{\beta}$-agonists. $\beta$-agonists are commonly used as bronchodilators in mechanically ventilated patients. ${ }^{62,83,94}$ While there are specific indications for the use of $\beta$-agonists in mechanically ventilated patients, they are now being utilized in many clinical situations where their benefits are unclear. ${ }^{88}$ High doses of albuterol administered via pMDI produced cough and tachycardia, ${ }^{17}$ and 3-6 times the routine nebulized dose of albuterol produced supraventricular and ventricular ectopy. ${ }^{19}$ The occurrence of tachyarrhythmias could be a concern in elderly patients with preexisting heart disease, atrial fibrillation, or prior history of ventricular tachycardia. The results of the large, multicenter BALTI study ${ }^{105}$ are somewhat reassuring in this regard. In this study, subjects receiving nebulized albuterol had a higher heart rate compared to those receiving placebo, but the occurrence of new-onset atrial fibrillation (10\% in both groups) and other dysrhythmias was similar in the 2 groups. However, in that study, nebulization of albuterol did not improve ventilator-free days or mortality, and the study was stopped early. ${ }^{105}$ In addition, the report that administration of $\beta$-agonists may increase the risk of VAP needs consideration. ${ }^{175}$

Widespread use of $\beta$-agonists in mechanically ventilated patients who do not have clear indications for their use, especially in high doses, have not been shown to lead to improvement in clinical outcomes and have the potential to be harmful. Thus, frequent and high doses of nebulized $\beta$-agonists should be avoided in mechanically ventilated patients unless there are specific indications for their use.

Intravenous Formulations. In the past, inhaled antibiotic solutions were made from intravenous formulations that contained preservatives, such as phenol and bisulfites. These solutions were often hypertonic, they did not have a neutral $\mathrm{pH}$, and the presence of the preservatives mentioned above contributed to airway irritation, coughing, 
and bronchoconstriction. ${ }^{176}$ Antibiotics for inhalation need to be specially formulated to avoid irritant effects. Drug solutions for inhalation should have osmolality of 150 $550 \mathrm{mOsm} / \mathrm{Kg}$, contain at least $77 \mathrm{mEq} / \mathrm{L}$ of chloride ions, and preferably have $\mathrm{pH}$ between 4.8 and $8 .{ }^{177-179}$ Solutions that do not contain ions (eg, dextrose solutions) are more likely to induce cough. Preservatives in drug solutions such as disodium ethylenediaminetetraacetic acid or benzalkonium chloride may cause bronchoconstriction or airway hyper-responsiveness that may not be completely abrogated by albuterol pretreatment. ${ }^{180-183}$

Drug Combinations. The presence of a preservative in a drug solution enhances nebulizer output, probably because of reduction in surface tension, compared to preservativefree solutions. ${ }^{184}$ Co-nebulization of albuterol with other drugs could unpredictably affect nebulizer output and aerosol characteristics. ${ }^{185}$ Addition of an albuterol solution containing benzalkonium chloride to a nebulizer solution of tobramycin increased tobramycin output without altering the particle size of the aerosol, ${ }^{186}$ and addition of surfactants to prevent foaming of a solution of alpha 1 protease inhibitor increased drug output. ${ }^{187}$ The physical and chemical compatibility of the drug mixtures also need to be confirmed, and this has been shown with several nebulizer solutions. ${ }^{188-190}$ For example, a solution of formoterol fumarate was found to be physically and chemically compatible with several other drug solutions. ${ }^{191}$ Drug admixtures or sequential administration produced higher drug output than nebulization of single drugs, but there was no significant change in the characteristics of the aerosol produced. Because of the unpredictable effects of drug admixtures, mixing drug solutions should be avoided in clinical practice.

\section{Provide Reproducibility of Dosing}

Drug dosing needs to be reproducible in ventilator-supported patients. Aerosol deposition is influenced by the age of the patient, body habitus and position, humidity, and the type and severity of lung disease. The lung deposition of radiolabeled aerosols in ventilated infants with bronchopulmonary dysplasia was as low as $0.98 \% \pm 0.2 \%$ and $0.22 \% \pm 0.1 \%$ with a pMDI and spacer or a jet nebulizer, respectively. ${ }^{192}$ The low efficiency of drug delivery is offset by the smaller size of the lung in infants and children. Compared to a standard $1.3 \mu \mathrm{g}$ of albuterol $/ \mathrm{kg}$ body weight delivered by each actuation from a VentolinHFA pMDI in a 70-kg, spontaneously breathing adult male, the range for spontaneously breathing infants and small children varies from 0.8 to $2.6 \mu \mathrm{g}$ of albuterol delivery $/ \mathrm{kg}$ body weight/actuation with a HFA-pMDI and Aerochamber Plus valved holding chamber. ${ }^{83}$ Inhaled bronchodilators ( $\beta$-adrenergic and anticholinergic drugs) are effective in ventilated neonates and infants with acute, subacute, and chronic lung disease. ${ }^{193-195}$ Albuterol administered with a pMDI and Aerochamber was found to be more effective than administration with a nebulizer. ${ }^{193,194}$ During infant mechanical ventilation, pMDIs appear to be more efficient than jet nebulizers; with a careful technique of administration, one or two doses from an albuterol pMDI and spacer chamber should suffice for routine therapy. In older children, the efficiency of pMDIs and nebulizers improve with increasing age, 137,196 and the factors influencing drug delivery are similar to those in adults. ${ }^{197}$ Obese individuals and those with COPD tend to have more central deposition of aerosols. ${ }^{54,198}$

The type of ventilator, mode of ventilation, and ventilatory parameters also influence aerosol deposition in the lung and the amount of exhaled aerosol. In view of the infinite variations of ventilator modes and settings possible in clinical practice, there cannot be a single recommended setting that is universally applicable for delivering aerosols during mechanical ventilation. Accordingly, aerosol therapy has to be individualized for patients and optimized to the appropriate clinical setting. Awareness of the complexity and nuances of aerosol delivery in ventilatorsupported patients is necessary to achieve successful outcomes. Guidelines are needed to help clinicians achieve best practices in a variety of clinical settings encountered in mechanically ventilated patients.

\section{Employ Clinically Feasible Methods}

Manual Resuscitation Bag. Ari and co-workers ${ }^{199}$ observed that a manual resuscitation bag connected to an ETT or tracheostomy tube produced a 3-fold higher aerosol delivery compared to other interfaces. This difference could be explained by the fact that capping the end of the tubing allows the circuit to be charged with the drug, and the drug was carried by the nebulizer flow to the collection filter. ${ }^{200}$ This method of drug administration could be employed when high doses of bronchodilators need to be rapidly administered in a patient with an artificial airway.

\section{Enhance Safety}

The administration of inhaled drugs to mechanically ventilated patients should be safe for patients, their caregivers, and the environment. With a jet nebulizer, the additional gas flow in the circuit could change the set flow and delivered tidal volume. Alarm settings should be adjusted if the ventilator does not compensate for additional gas flow from the nebulizer. Such adjustments are especially important in ventilator-dependent children. If ventilator settings are changed during aerosol administration, they should be returned to the pretreatment settings at the conclusion of the treatment. 
Ventilator Settings. The technique employed may have to compromise between the optimum operating characteristics of the device and the patient's condition. For example, a higher duty cycle increases aerosol delivery, ${ }^{10,11,13}$ but it may worsen dynamic hyperinflation in patients with air flow limitation. ${ }^{148}$ A higher tidal volume may be advantageous for aerosol delivery, but could be injurious to the lungs, especially in patients with ARDS. ${ }^{201}$

Cleaning. Unless scrupulously cleaned and disinfected, nebulizers can be a source for aerosolization of bacteria and thus may predispose patients to nosocomial pneumonia. ${ }^{86}$ Because of their design, the risk of bacterial contamination may be less with vibrating mesh nebulizers compared to jet nebulizers. The gas flow driving the nebulizer produces additional air flow in the ventilator circuit, but this is compensated for in most modern ventilators. In contrast, pMDIs are easy to administer, require less personnel time, provide a reliable dose, and do not pose a risk of bacterial contamination. A retrospective analysis of patients receiving ventilator support for $>1 \mathrm{~d}$ and aerosol treatments by pMDI or vibrating mesh nebulizer found no differences in the number of days on ventilator (median $5 / 6$ d), VAP rates $(5 / 6 \%)$, or in-hospital mortality. ${ }^{202}$

\section{Circuit Contamination and Frequent Disconnection.} Jet nebulizers are usually attached to the ventilator circuit with a standard T-adapter, and attaching or removing the nebulizer from the ventilator circuit may interrupt ventilation. Valved T-adaptors allow placement and removal of the jet nebulizer without loss of pressure in the ventilator circuit. In-line devices that avoid breaking the circuit integrity are preferred. Placing vibrating mesh nebulizers on the dry side of the humidifier reduces the concern for repeatedly breaking the circuit. For the same reason, collapsible spacers that remain in the circuit are preferred for use with pMDIs compared to devices that have to be removed from the circuit after each treatment.

Blockage of Expiratory Filter. Nebulization of drugs could produce obstruction of the filter in the expiratory limb of the ventilator circuit. ${ }^{203}$ When this occurs acutely, it can mimic an exacerbation of asthma or lead to more serious consequences, including tension pneumothorax, hypoxemia, or cardiovascular collapse. Obstruction of the filter is more likely to occur with continuous nebulization when the filter becomes supersaturated with humidity and with the use of unheated ventilator circuits. ${ }^{204}$ Moreover, drug particles in the aerosol or sticky buffers in the drug solution may also contribute to filter blockage. ${ }^{205}$ The expiratory filter should be checked when any mechanically ventilated patient develops unexplained acute bronchospasm or PEEP.
Drug Toxicity. Bronchospasm occurs after inhaled antimicrobials, especially after colistin administration, ${ }^{206,207}$ and requires pretreatment with a short-acting bronchodilator such as albuterol. ${ }^{208,209}$ The occurrence of bronchospasm is reduced, but not totally avoided, by using the preservative-free inhalable tobramycin rather than the intravenous formulation. ${ }^{210,211}$ Bronchospasm in some patients with asthma may be refractory to albuterol. ${ }^{209}$

Administration of high doses of $\beta$-adrenergic bronchodilators causes tachycardia and has the potential to cause atrial and ventricular arrhythmias. ${ }^{19}$ In the ARDS Network BALTI study, regular administration of nebulized albuterol produced a significant but modest increase in heart rate but did not result in an increased incidence of atrial fibrillation or ventricular arrhythmias. ${ }^{105}$

Escape of aerosols into the environment carries potential risks for the environment and persons caring for the patient. ${ }^{212,213}$ Escape of antibiotics into the environment could pose serious health risks, such as anaphylaxis in patients or caregivers with a penicillin allergy. Inhalation of aerosolized antimicrobials, particularly pentamidine and polymyxin, has the potential to cause adverse effects on healthcare workers. In addition, a low level of antibiotic exposure in the environment could promote growth of antibiotic-resistant organisms. ${ }^{211,214}$ The escape of aerosols into the environment could be reduced by utilizing breathactuated aerosol delivery devices and high-efficiency particulate filters in the expiratory limb to filter the exhaled air.

Cough and Spread of Infection. In an era of serious infections for which there are no or limited treatment options, such as Ebola, severe acute respiratory syndrome, Middle East Respiratory Syndrome, H1N1 influenza, or extremely drug-resistant tuberculosis, treatments that induce coughing could lead to transmission of infection. ${ }^{215}$

\section{Control Costs}

The costs of therapy include both direct and indirect costs. Besides the costs of drugs and devices, the costs of respiratory therapists' time, and the costs associated with monitoring and hospital stay must be considered. Ely and co-workers ${ }^{91}$ estimated that the costs of giving bronchodilators via pMDIs and nebulizers contributed a significant portion of the total costs of respiratory care in mechanically ventilated subjects. However, the costs of therapy could be influenced by the clinical indication. For example, the costs of administering antibiotics or prostanoids are expected to be higher than those associated with administration of bronchodilators. The cost of a particular treatment is also influenced by the expense, efficacy, and side effects of comparative treatment. Finally, cost is also relative to clinical outcomes. The economics of utilizing 


\section{Aerosol Delivery During Invasive Mechanical Ventilation}

inhaled therapies depends on cost-minimization, cost-effectiveness, cost-benefit, and cost-utility strategies that could influence which drugs and devices are used in ventilator-dependent patients. ${ }^{216}$ Thus, therapies that improve mortality and reduce days of mechanical ventilation or ICU stay may be more expensive, but they are considered more cost-effective and are likely to gain greater acceptance than less expensive interventions that less favorably influence clinical outcomes. ${ }^{217}$

\section{Summary}

Aerosol delivery in mechanically ventilated patients differs from the administration of inhaled therapies in spontaneously breathing ambulatory patients in many respects. The techniques of administration required to achieve efficient delivery of aerosols in ventilated patients are well known and take into consideration a host of factors. The delivery of aerosols through ventilator circuits has the potential advantage that the upper airway is bypassed with an artificial airway, and the timing of aerosol administration and breathing parameters could be better controlled. The presence of heat and humidity in the ventilator circuit, however, reduces the efficiency of drug delivery and requires administration of higher doses than those routinely employed in spontaneously breathing patients. Furthermore, no specific therapies have been approved as yet for use during mechanical ventilation, and the effect of inhaled therapies on clinical outcomes needs further study. A goal-directed approach as outlined in this review could enhance the efficiency of aerosol delivery and ensure more reliable and consistent drug dosing during mechanical ventilation. In view of the complexity of aerosol administration in this clinical setting and the importance of following an optimal technique of administration to achieve the desired therapeutic effects, updated guidelines are needed to establish best practices for aerosol delivery across a variety of clinical settings encountered in ventilator-supported patients.

\section{REFERENCES}

1. Wunsch H, Linde-Zwirble WT, Angus DC, Hartman ME, Milbrandt EB, Kahn JM. The epidemiology of mechanical ventilation use in the United States. Crit Care Med 2010;38(10):1947-1953.

2. American Association for Respiratory Care. Aerosol consensus statement: 1991. Respir Care 1991;36(9):916-921.

3. MacIntyre NR, Silver RM, Miller CW, Schuler F, Coleman RE. Aerosol delivery in intubated, mechanically ventilated patients. Crit Care Med 1985;13(2):81-84.

4. Fuller HD, Dolovich MB, Posmituck G, Pack WW, Newhouse MT. Pressurized aerosol versus jet aerosol delivery to mechanically ventilated patients. Comparison of dose to the lungs. Am Rev Respir Dis 1990;141(2):440-444.

5. Dhand R, Tobin MJ. Inhaled bronchodilator therapy in mechanically ventilated patients. Am J Respir Crit Care Med 1997;156(1): 3-10.
6. Dhand R. Nebulizers that use a vibrating mesh or plate with multiple apertures to generate aerosol. Respir Care 47(12):1406-1416, 2002; discussion 1416-1418.

7. Dolovich MB, Dhand R. Aerosol drug delivery: developments in device design and clinical use. Lancet 2011;377(9770):1032-1045.

8. Laube BL, Janssens HM, de Jongh FHC, Devadason S, Dhand R, Diot P, et al. ERS/ISAM Task Force Report: What the pulmonary specialist should know about the new inhalation therapies. Eur Respir J 2011;37(6):1308-1331.

9. Ari A, Fink JB, Dhand R. Inhalation therapy in patients receiving mechanical ventilation: an update. J Aerosol Med Pulm Drug Deliv 2012;25(6):319-332.

10. Fink JB, Dhand R, Duarte AG, Jenne JW, Tobin MJ. Aerosol delivery from a metered-dose inhaler during mechanical ventilation. An in-vitro model. Am J Respir Crit Care Med 1996;154(2 Pt1):382-387.

11. Fink JB, Dhand R, Grychowski J, Fahey PJ, Tobin MJ. Reconciling in-vitro and in-vivo measurements of aerosol delivery from a metered-dose inhaler during mechanical ventilation, and defining efficiency enhancing factors. Am J Respir Crit Care Med 1999;159(1): 63-68.

12. Vecellio L, Guérin C, Grimbert D, De Monte M, Diot P. In vitro study and semiempirical model for aerosol delivery control during mechanical ventilation. Intensive Care Med 2005;31(6):871-876.

13. O'Riordan TG, Palmer LB, Smaldone GC. Aerosol deposition in mechanically ventilated patients: optimizing nebulizer delivery. Am J Respir Crit Care Med 1994;149(1):214-219.

14. Duarte AG, Dhand R, Reid R, Fink JB, Fahey PJ, Tobin MJ, Jenne JW. Serum albuterol levels in mechanically ventilated patients and healthy subjects after metered-dose inhaler administration. Am J Respir Crit Care Med 1996;154(6 Pt1):1658-1663.

15. Marik P, Hogan J, Krikorian J. A comparison of bronchodilator therapy delivered by nebulization and metered-dose inhaler in mechanically ventilated patients. Chest 1999;115(6):1653-1657.

16. Miller DD, Amin MM, Palmer LB, Shah AR, Smaldone GC. Aerosol delivery and modern mechanical ventilation: in vitro/in vivo evaluation. Am J Respir Crit Care Med 2003;168(10):1205-1209.

17. Dhand R, Duarte AG, Jubran A, Jenne JW, Fink JB, Fahey PJ, Tobin MJ. Dose-response to bronchodilator delivered by metereddose inhaler in ventilator-supported patients. Am J Respir Crit Care Med 1996;154(2 Pt1):388-393.

18. Duarte AG, Momii K, Bidani A. Bronchodilator therapy with metered-dose inhaler and spacer versus nebulizer in mechanically ventilated patients: comparison of magnitude and duration of response. Respir Care 2000;45(7):817-823.

19. Manthous CA, Hall JB, Schmidt GA, Wood LD. Metered-dose inhaler versus nebulized albuterol in mechanically ventilated patients. Am Rev Respir Dis 1993;148(6 Pt 1):1567-1570.

20. Manthous CA, Chatila W, Schmidt GA, Hall JB. Treatment of bronchospasm by metered-dose inhaler albuterol in mechanically ventilated patients. Chest 1995;107(1):210-213.

21. Dolovich MB, Ahrens RC, Hess DR, Anderson P, Dhand R, Rau JL, et al. Device selection and outcomes of aerosol therapy: evidencebased guidelines: American College of Chest Physicians/ American College of Asthma, Allergy, and Immunology. Chest 2005;127(1): 335-371.

22. Mouloudi E, Maliotakis C, Kondili E, Kafetzakis A, Georgopoulos D. Duration of salbutamol-induced bronchodilation delivered by metered-dose inhaler in mechanically ventilated COPD patients. Monaldi Arch Chest Dis 2001;56(3):189-194.

23. Dhand R, Guntur VP. How best to deliver aerosol medications to mechanically ventilated patients. Clin Chest Med 2008;29(2):277296. 


\section{Aerosol Delivery During Invasive Mechanical Ventilation}

24. Georgopoulos D, Mouloudi E, Kondili E, Klimathianaki M. Bronchodilator delivery with metered-dose inhaler during mechanical ventilation. Crit Care 2000;4(4):227-234.

25. Dhand R. Inhalation therapy with metered-dose inhalers and dry powder inhalers in mechanically ventilated patients. Respir Care 2005;50(10):1331-1334; discussion 1344-1345.

26. Rau JL, Dunlevy CL, Hill RL. A comparison of inline MDI actuators for delivery of a beta agonist and a corticosteroid with a mechanically ventilated lung model. Respir Care 1998;43(9):705712.

27. Rau JL, Harwood RJ, Groff JL. Evaluation of a reservoir device for metered-dose bronchodilator delivery to intubated adults. An in vitro study. Chest 1992;102(3):924-930.

28. Dhand R, Tobin MJ. Bronchodilator delivery with metered-dose inhalers in mechanically ventilated patients. Eur Respir J 1996;9(3): 585-595.

29. Taylor RH, Lerman J, Chambers C, Dolovich M. Dosing efficiency and particle-size characteristics of pressurized metered-dose inhaler aerosols in narrow catheters. Chest 1993;103(3):920-924.

30. Diot P, Morra L, Smaldone GC. Albuterol delivery in a model of mechanical ventilation. Comparison of metered-dose inhaler and nebulizer efficiency. Am J Respir Crit Care Med 1995;152(4 pt1): 1391-1394.

31. Thomas SH, O'Doherty MJ, Page CJ, Treacher DF, Nunan TO. Delivery of ultrasonic nebulized aerosols to a lung model during mechanical ventilation. Am Rev Respir Dis 1993;148(4 Pt1):872877.

32. Fink JB. Metered-dose inhalers, dry powder inhalers and transitions. Respir Care 2000;45(6):623-635.

33. Everard ML, Devadason SG, Summers QA, Le Souëf PN. Factors affecting total and "respirable" dose delivered by a salbutamol metered dose inhaler. Thorax 1995;50(7):746-749.

34. Niven RW, Kacmarek RM, Brain JD, Peterfreund RA. Small bore nozzle extensions to improve the delivery efficiency of drugs from metered-dose inhalers: laboratory evaluation. Am Rev Respir Dis 1993;147(6 Pt1):1590-1594.

35. Spahr-Schopfer IA, Lerman J, Cutz E, Newhouse MT, Dolovich M. Proximate delivery of a large experimental dose from salbutamol MDI induces epithelial airway lesions in intubated rabbits. Am J Respir Crit Care Med 1994;150(3):790-794.

36. Dhand R, Jubran A, Tobin MJ. Bronchodilator delivery by metereddose inhaler in ventilator-supported patients. Am J Respir Crit Care Med 1995;151(6):1827-1833.

37. Ari A, Areabi H, Fink JB. Evaluation of aerosol generator devices at 3 locations in humidified and non-humidified circuits during adult mechanical ventilation. Respir Care 2010;55(7):837-844.

38. Rau JL. Design principles of liquid nebulization devices currently in use. Respir Care 47(11):1257-1275, 2002; discussion 1275-1278.

39. Dalby RN, Tiano SL, Hickey AJ. Medical devices for the delivery of therapeutic aerosols to the lungs. In: Hickey AJ, ed. Inhalation Aerosols: Physical and Biological Basis for Therapy. New York: Marcel Dekker, 1996;441-473.

40. Hess DR. Nebulizers: principles and performance. Respir Care 2000; 45(6):609-622

41. Alvine GF, Rodgers P, Fitzsimmons KM, Ahrens RC. Disposable jet nebulizers. How reliable are they? Chest 1992;101(2):316-319.

42. Loffert DT, Ikle D, Nelson HS. A comparison of commercial jet nebulizers. Chest 1994;106(6):1788-1792.

43. Hess D, Fisher D, Williams P, Pooler S, Kacmarek RM. Medication nebulizer performance. Effects of diluent volume, nebulizer flow, and nebulizer brand. Chest 1996;110(2):498-505.

44. Phipps PR, Gonda I. Droplets produced by medical nebulizers. Some factors affecting their size and solute concentration. Chest 1990;97(6):1327-1332.
45. Steckel H, Eskandar F. Factors affecting aerosol performance during nebulization with jet and ultrasonic nebulizers. Eur J Pharm Sci 2003;19(5):443-455.

46. Watts AB, McConville JT, Williams RO. Current therapies and technological advances in aqueous aerosol drug delivery. Drug Dev Ind Pharm 2008;34(9):913-922.

47. Kemming GI, Kreyling W, Habler O, Merkel M, Kleen M, Welte $\mathrm{M}$, et al. Aerosol production and aerosol droplet size distribution during mechanical ventilation (IPPV) with a new ultrasonic nebulizer. Eur J Med Res 1996;1(7):321-327.

48. Harvey CJ, O’Doherty MJ, Page CJ, Thomas SH, Nunan TO, Treacher DF. Comparison of jet and ultrasonic nebulizer pulmonary aerosol deposition during mechanical ventilation. Eur Respir J 1997; 10(4):905-909.

49. Williams L, Fletcher GC, Daniel M, Kinsella J. A simple in vitro method for the evaluation of an ultrasonic nebulizer for drug delivery to intubated, ventilated patients and the effect of nebulizer and ventilator settings on the uptake of fluid from the nebulizer chamber. Eur J Anaesthesiol 1999;16(7):479-484.

50. Phillips GD, Millard FJL. The therapeutic use of ultrasonic nebulizers in acute asthma. Respir Med 1994;88(5):387-389.

51. O'Doherty MJ, Thomas SH, Page CJ, Treacher DF, Nunan TO. Delivery of a nebulized aerosol to a lung model during mechanical ventilation. Effect of ventilator settings and nebulizer type, position, and volume of fill. Am Rev Respir Dis 1992;146(2):383-388.

52. ElHansy MH, Boules ME, Farid H, Chrystyn H, El-Maraghi SK, Al-Kholy MB, et al. In vitro aerodynamic characteristics of aerosol delivered from different inhalation methods in mechanical ventilation. Pharm Dev Technol 2016;30:1-6.

53. Diot P, Magro P, Vecellio L, Smaldone GC. Advances in our understanding of aerosolized iloprost for pulmonary hypertension. $\mathrm{J}$ Aerosol Med 2006;19(3):406-407.

54. Smaldone GC. Advances in aerosols: adult respiratory disease. J Aerosol Med 2006;19(1):36-46.

55. Van Dyke RE, Nikander K. Delivery of iloprost inhalation solution with the HaloLite, Prodose, and I-neb Adaptive Aerosol Delivery systems: an in vitro study Respir Care 2007;52(2):184-190.

56. Waldrep JC, Dhand R. Advanced nebulizer designs employing vibrating mesh/aperture plate technologies for aerosol generation. Curr Drug Deliv 2008;5(2):114-119.

57. Waldrep JC, Berlinski A, Dhand R. Comparative analysis of methods to measure aerosols generated by a vibrating mesh nebulizer. J Aerosol Med 2007;20(3):310-319.

58. Johnson JC, Waldrep JC, Guo J, Dhand R. Aerosol delivery of recombinant human DNase I: in vitro comparison of a vibratingmesh nebulizer with a jet nebulizer. Respir Care 2008;53(12):17031708.

59. Ruickbie S, Hall A, Ball J. Therapeutic aerosols in mechanically ventilated patients. In: Vincent J, editor. Annual Update in Intensive Care and Emergency Medicine 2011. Berlin, Heidelberg: Springer; 2011. p. 197-206.

60. Rubin BK. Pediatric aerosol therapy: new devices and new drugs. Respir Care 56(9):1411-1421, 2011; discussion 1421-1423.

61. Gowda AA, Cuccia AD, Smaldone GC. Reliability of vibrating mesh technology. Respir Care 2017;62(1):65-69.

62. Ehrmann S, Roche-Campo F, Bodet-Contentin L, Razazi K, Dugernier J, Trenado-Alvarez J, et al. Aerosol therapy in intensive and intermediate care units: prospective observation of 2808 critically ill patients. Intensive Care Med 2016;42(2):192-201.

63. Ehrmann S, Lyazidi A, Louis B, Isabey D, Le Pennec D, Brochard L, Apriou-Sbirlea G. Ventilator-integrated jet nebulization systems: tidal volume control and efficiency of synchronization. Respir Care 2014;59(10):1508-1516. 


\section{Aerosol Delivery During Invasive Mechanical Ventilation}

64. Dhand R, Sohal H. Pulmonary Drug Delivery System for inhalation therapy in mechanically ventilated patients. Expert Rev Med Devices 2008;5(1):9-20.

65. Niederman MS, Chastre J, Corkery K, Fink JB, Luyt CE, García MS. BAY41-6551 achieves bactericidal tracheal aspirate amikacin concentrations in mechanically ventilated patients with Gram-negative pneumonia. Intensive Care Med 2012;38(2):263-271.

66. Ari A, Atalay OT, Harwood R, Sheard MM, Aljamhan EA, Fink JB. Influence of nebulizer type, position, and bias flow on aerosol drug delivery in simulated pediatric and adult lung models during mechanical ventilation. Respir Care 2010;55(7):845-851.

67. O'Riordan TG, Greco MJ, Perry RJ, Smaldone GC. Nebulizer function during mechanical ventilation. Am Rev Respir Dis 1992;145(5): 1117-1122.

68. Hughes JM, Saez J. Effects of nebulizer mode and position in a mechanical ventilator circuit on dose efficiency. Respir Care 1987; 32(12):1131-1135.

69. Wan GH, Lin HL, Fink JB, Chen YH, Wang WJ, Chiu YC, et al. In vitro evaluation of aerosol delivery by different nebulization modes in pediatric and adult mechanical ventilators. Respir Care 2014;59(10):1494-1500.

70. Moraine JJ, Truflandier K, Vandenbergen N, Berre J, Melot C, Vincent JL. Placement of the nebulizer before the humidifier during mechanical ventilation: effect on aerosol delivery. Heart Lung 2009; 38(5):435-439.

71. Dhand R. Aerosol therapy during mechanical ventilation: getting ready for prime time. Am J Respir Crit Care Med 2003;168(10): 1148-1149.

72. Siobal MS, Kallet RH, Pittet J-F, Warnecke EL, Kraemer RW, Venkayya RV, Tang JF. Description and evaluation of a delivery system for aerosolized prostacyclin. Respir Care 2003;48(8):742753.

73. Pitance L, Vecellio L, Leal T, Reychler G, Reychler H, Liistro G. Delivery efficacy of a vibrating mesh nebulizer and a jet nebulizer under different configurations. J Aerosol Med Pulm Drug Deliv 2010;23(6):389-396.

74. Dhand R. Aerosol delivery during mechanical ventilation: from basic techniques to new devices. J Aerosol Med Pulm Drug Deliv 2008;21(1):45-60.

75. Dellweg D, Wachtel H, Höhn E, Pieper MP, Barchfeld T, Köhler D, Glaab T. In vitro validation of a Respimat ${ }^{\circledR}$ adapter for delivery of inhaled bronchodilators during mechanical ventilation. J Aerosol Med Pulm Drug Deliv 2011;24(6):285-292.

76. Everard ML, Devadason SG, Le Souef PN. In vitro assessment of drug delivery through an endotracheal tube using a dry powder inhaler delivery system. Thorax 1996;51(1):75-77.

77. Jashnani RN, Byron PR, Dalby RN. Testing of dry powder aerosol formulations in different environmental conditions. Int J Pharm 1995;113(1):123-130.

78. Tronde A, Baran G, Eirefelt S, Lennernäs H, Bengtsson UH. Miniaturized nebulization catheters: a new approach for delivery of defined aerosol doses to the rat lung. J Aerosol Med 2002;15(3): 283-296.

79. Köping-Höggård M, Issa MM, Köhler T, Tronde A, Vårum Km, and Artursson P. A miniaturized nebulization catheter for improved gene delivery to the mouse lung. J Gene Med 2005;7(9):1215-1222.

80. Selting K, Waldrep JC, Reinero C, Branson K, Gustafson D, Kim DY, et al. Feasibility and safety of targeted cisplatin delivery to a select lung lobe in dogs via the AeroProbe intracorporeal nebulization catheter. J Aerosol Med Pulm Drug Deliv 2008;21(3):255268.

81. Selting K, Essman S, Reinero C, Branson KR, Henry CJ, Owen N, et al. Targeted combined aerosol chemotherapy in dogs and radio- logic toxicity grading. J Aerosol Med Pulm Drug Deliv 2011;24(1): 43-48.

82. Guerin C, Chevre A, Dessirier P, Poncet T, Becquemin MH, Dequin $\mathrm{PF}$, et al. Inhaled fenoterol-ipratropium bromide in mechanically ventilated patients with chronic obstructive pulmonary disease. Am J Respir Crit Care Med 1999;159(4 Pt1):1036-1042.

83. Dhand R. Bronchodilator Therapy. Tobin MJ, editor. Principles and Practice of Mechanical Ventilation. 3rd edition. New York: McGraw Hill; 2013:1419-1446.

84. Gilmore T. Use of a metered-dose inhaler compared with a vibrating mesh nebulizer during mechanical ventilation: does it really matter? Respir Care 2017;62(4):513-514.

85. Craven DE, Lichtenberg DA, Goularte TA, Make BJ, McCabe WR. Contaminated medication nebulizers in mechanical ventilator circuits: source of bacterial aerosols. Am J Med 1984;77(5):834-838.

86. Hamill RJ, Houston ED, Georghiou PR, Wright CE, Koza MA, Cadle RM, et al. An outbreak of Burkholderia (formerly Pseudomonas) cepacia respiratory tract colonization and infection associated with nebulized albuterol therapy. Ann Intern Med 1995;122(10): 762-766.

87. Ballard J, Lugo RA, Salyer JW. A survey of albuterol administration practices in intubated patients in the neonatal intensive care unit. Respir Care 2002;47(1):31-38.

88. Chang LH, Honiden S, Haithcock JA, Das AM, Short KA, Nierman DM, Carson SS. Utilization of bronchodilators in ventilated patients without obstructive airways disease. Respir Care 2007;52(2): 154-158.

89. Summer W, Elston R, Tharpe L, Nelson S, Haponik EF. Aerosol bronchodilator delivery methods. Relative impact on pulmonary function and cost of respiratory care. Arch Intern Med 1989;149(3): 618-623.

90. Bowton DL, Goldsmith WM, Haponik EF. Substitution of metereddose inhalers for hand-held nebulizers. Success and cost savings in a large, acute-care hospital. Chest 1992;101(2):305-308.

91. Ely EW, Baker AM, Evans GW, Haponik EF. The distribution of costs of care in mechanically ventilated patients with chronic obstructive pulmonary disease. Crit Care Med 2000;28(2):408-413.

92. Holland A, Smith F, Penny K, McCrossan G, Veitch L, Nicholson C. Metered dose inhalers versus nebulizers for aerosol bronchodilator delivery for adult patients receiving mechanical ventilation in critical care units. Cochrane Database Syst Rev. 2013 Jun 6;(6): CD008863.

93. Dhand R, Mercier E. Effective inhaled drug administration to mechanically ventilated patients. Expert Opin Drug Deliv 2007;4(1): 47-61.

94. Ehrmann S, Roche-Campo F, Sferrazza Papa GF, Isabey D, Brochard L, Apiou-Sbirlea G; REVA Research Network. Aerosol therapy during mechanical ventilation: an international survey. Intensive Care Med 2013;39(6):1048-1056.

95. Boucher BA, Kuhl DA, Coffey BC, Fabian TC. Drug use in a trauma intensive-care unit. Am J Hosp Pharm 1990;47(4):805-810.

96. Wollam PJ, Kasper CL, Bishop MJ, Pierson DJ. Prediction and assessment of bronchodilator response in mechanically ventilated patients. Respir Care 1994;39(7):730-737.

97. Tzoufi M, Mentzelopoulos SD, Roussos C, Armaganidis A. The effects of nebulized salbutamol, external positive end-expiratory pressure, and their combination on respiratory mechanics, hemodynamics, and gas exchange in mechanically ventilated chronic obstructive pulmonary disease patients. Anesth Analg 2005;101(3): 843-850.

98. Gay PC, Rodarte JR, Tayyab M, Hubmayr RD. Evaluation of bronchodilator responsiveness in mechanically ventilated patients. Am Rev Respir Dis 1987;136(4):880-885. 


\section{Aerosol Delivery During Invasive Mechanical Ventilation}

99. Wright PE, Carmichael LC, Bernard GR. Effect of bronchodilators on lung mechanics in the acute respiratory distress syndrome (ARDS). Chest 1994;106(5):1517-1523.

100. Morina P, Herrera M, Venegas J, Mora D, Rodríguez M, Pino E. Effects of nebulized salbutamol on respiratory mechanics in adult respiratory distress syndrome. Intensive Care Med 1997;23(1):5864.

101. Mancebo J, Amaro P, Lorino H, Lemaire F, Harf A, Brochard L. Effects of albuterol inhalation on the work of breathing during weaning from mechanical ventilation. Am Rev Respir Dis 1991; 144(1):95-100.

102. Fernandez A, Munoz J, de la Calle B, Alia I, Ezpeleta A, de la Cal MA, Reyes A. Comparison of one versus two bronchodilators in ventilated COPD patients. Intensive Care Med 1994;20(3):199-202.

103. Bennett WD. Effect of beta-adrenergic agonists on mucociliary clearance. J Allergy Clin Immunol 2002;110(6 Suppl):S291-S297.

104. McAuley DF, Frank JA, Fang X, Matthay MA. Clinically relevant concentrations of beta2-adrenergic agonists stimulate maximal cyclic adenosine monophosphate-dependent airspace fluid clearance and decrease pulmonary edema in experimental acid-induced lung injury. Crit Care Med 2004;32(7):1470-1476.

105. National Heart, Lung, and Blood Institute Acute Respiratory Distress Syndrome (ARDS) Clinical Trials Network, Matthay MA, Brower RG, Carson S, Douglas IS, Eisner M, et al. Randomized, placebo-controlled clinical trial of an aerosolized $\beta_{2}$-agonist for treatment of acute lung injury. Am J Respir Crit Care Med 2011; 184(5):561-568.

106. Abramson MJ, Walters J, Walters EH. Adverse effects of betaagonists: are they clinically relevant? Am J Respir Med 2003;2(4): 287-297.

107. Kleerup EC, Tashkin DP, Cline AC, Ekholm BP. Cumulative doseresponse study of non-CFC propellant HFA-134a salbutamol sulfate metered-dose inhaler in patients with asthma. Chest 1996; 109(3):702-707.

108. Ramsdell JW, Colice GL, Ekholm BP, Klinger NM. Cumulative dose response study comparing HFA-134a albuterol sulfate and conventional CFC albuterol in patients with asthma. Ann Allergy Asthma Immunol 1998;81(6):593-599.

109. Dhand R. Bronchodilator therapy in mechanically ventilated patients: patient selection and clinical outcomes. Respir Care 2007; 52(2):152-153.

110. Le Brun PP, de Boer AH, Heijerman HG, Frijlink HW. A review of the technical aspects of drug nebulization. Pharm World Sci 2000; 22(3):75-81.

111. Luyt CE, Clavel M, Guntupalli K, Johannigman J, Kennedy JI, Wood C, et al. Pharmacokinetics and lung delivery of PDDS-aerosolized amikacin (NKTR-061) in intubated and mechanically ventilated patients with nosocomial pneumonia. Critical Care 2009;13: R200. doi:10.1186/cc8206.

112. Kalil AC, Metersky ML, Klompas M, Muscedere J, Sweeney DA, Palmer LB, et al. Management of adults with hospital-acquired and ventilator-associated pneumonia: 2016 Clinical Practice Guidelines by the Infectious Diseases Society of America and the American Thoracic Society. Clin Infect Dis 2016;63(5):e61-e111.

113. Solé-Lleonart C, Rouby JJ, Blot S, Poulakou G, Chastre J, Palmer LB, et al. Nebulization of antiinfective agents in invasively mechanically ventilated adults: a systematic review and meta-analysis. Anesthesiology 2017;126(5):890-908.

114. Kollef MH, Ricard JD, Roux D, Francois B, Ischaki E, Rozgonyi Z, et al. A randomized trial of the amikacin fosfomycin inhalation system for the adjunctive therapy of gram-negative ventilator-associated pneumonia: IASIS Trial. Chest 2017;151(6):1239-1246.
115. Squara P, Dhainaut JF, Artigas A, Carlet J. Hemodynamic profile in severe ARDS: results of the European Collaborative ARDS Study. Intensive Care Med 1998;24(10):1018-1028.

116. DiBlasi RM, Meyer TR, Hess DR. Evidence-based clinical practice guidelines: inhaled nitric oxide for neonates with acute hypoxic respiratory failure. Respir Care 2010;55(12):1717-1745.

117. Puri N, Dellinger RP. Inhaled nitric oxide and inhaled prostacyclin in acute respiratory distress syndrome: what is the evidence? Crit Care Clin 2011;27(3):561-587.

118. Bihari D, Smithies M, Gimson A, Tinker J. The effects of vasodilation with prostacyclin on oxygen delivery and uptake in critically ill patients. N Engl J Med 1987;317(7):397-403.

119. Radermacher P, Santak B, Wust HJ, Tarnow J, Falke KJ. Prostacyclin for the treatment of pulmonary hypertension in the adult respiratory distress syndrome: effects on pulmonary capillary pressure and ventilation-perfusion distributions. Anesthesiology 1990; 72(2):238-244.

120. Haraldsson A, Kieler-Jensen N, Ricksten SE. Inhaled prostacyclin for treatment of pulmonary hypertension after cardiac surgery or heart transplantation: a pharmacodynamic study. J Cardiothorac Vasc Anesth 1996;10(7):864-868.

121. Meyer J, Theilmeier G, Van Aken H, Bone HG, Busse H, Waurick R, Hinder F, Booke M. Inhaled prostaglandin $\mathrm{E}_{1}$ for the treatment of acute lung injury in severe multiple organ failure. Anesth Analg 1998;86(4):753-758.

122. Walmrath D, Schneider T, Schermuly R, Olschewski H, Grimminger F, Seeger W. Direct comparison of inhaled nitric oxide and aerosolized prostacyclin in adult respiratory distress syndrome. Am J Respir Crit Care Med 1996;153(3):991-996.

123. Zwissler B, Kemming G, Habler O, Kleen M, Merkel M, Haller M, et al. Inhaled prostacyclin (PGI2) versus inhaled nitric oxide in adult respiratory distress syndrome. Am J Respir Crit Care Med 1996;154(6Pt1):1671-1677.

124. Putensen C, Hormann C, Kleinsasser A, Putensen-Himmer G. Cardiopulmonary effects of aerosolized prostaglandin $E_{1}$ and nitric oxide inhalation in patients with acute respiratory distress syndrome. Am J Respir Crit Care Med 1998;157(6 Pt 1):1743-1747.

125. Fuller BM, Mohr NM, Skrupky L, Fowler S, Kollef MH, Carpenter CR. The use of inhaled prostaglandins in patients with ARDS. Chest 2015;147(6):1510-1522.

126. Siddiqui S, Salahuddin N, Zubair S, Yousuf M, Azam 1, Gilani AH Use of inhaled $\mathrm{PGE}_{1}$ to improve diastolic dysfunction, LVEDP, pulmonary hypertension and hypoxia in ARDS: a randomized clinical trial. Open J Anesthesiol 2013;3:109-115.

127. Ammar MA, Bauer SR, Bass SN, Sasidhar M, Mullin R, Lam SW. Noninferiority of inhaled epoprostenol to inhaled nitric oxide for the treatment of ARDS. Ann Pharmacother 2015;49(10):1105-1112.

128. Dhand R. Special problems in aerosol delivery: artificial airways. Respir Care 2000;45(6):636-645.

129. Crogan SJ, Bishop MJ. Delivery efficiency of metered dose aerosols given via endotracheal tubes. Anesthesiology 1989;70(6):10081010.

130. Ahrens RC, Ries RA, Popendorf W, Wiese JA. The delivery of therapeutic aerosols through endotracheal tubes. Pediatr Pulmonol 1986;2(1):19-26.

131. Takaya T, Takeyama K, Takiguchi M. The efficiency of beta2agonist delivery through tracheal tubes with the metered-dose inhaler: an in vitro study. J Anesth 2002;16(4):284-288.

132. Ari A, Harwood RJ, Sheard MM, Fink JB. Pressurized metereddose inhalers versus nebulizers in the treatment of mechanically ventilated subjects with artificial airways: an in vitro study. Respir Care 2015;60(11):1570-1574.

133. Piccuito CM, Hess DR. Albuterol delivery via tracheostomy tubes. Respir Care 2005;50(8):1071-1076. 


\section{Aerosol Delivery During Invasive Mechanical Ventilation}

134. Pitance L, Vecellio L, Delval G, Reychler G, Reychler H, Liistro G. Aerosol delivery through tracheostomy tubes: an in vitro study. J Aerosol Med Pulm Drug Deliv 2013;26(2):76-83.

135. Fuller H, Dolovich M, Turpie F, Posmituck G, Wong Pack W, Newhouse M. Aerosol deposition to the lungs by MDI in ventilated patients: endotracheal tubes vs tracheostomy. Chest 1990;98(2 Suppl):27S.

136. Fuller HD, Dolovich MB, Chambers C, Newhouse MT. Aerosol delivery during mechanical ventilation: a predictive in vitro lung model. J Aerosol Med 1992;5(4):251-259.

137. Garner SS, Wiest DB, Bradley JW. Aerosol delivery by metereddose inhaler with a pediatric mechanical ventilatory circuit model. Pharmacotherapy 1994;14(2):210-214.

138. Lange CF, Finlay WH. Overcoming the adverse effect of humidity in aerosol delivery via pressurized metered-dose inhalers during mechanical ventilation. Am J Respir Crit Care Med 2000;161(5): 1614-1618.

139. Lin HL, Fink JB, Zhou Y, Cheng Y-S. Influence of moisture accumulation in inline spacer on delivery of metered dose inhaler through mechanical ventilation. Respir Care 2009;54(10):13361341.

140. Wilkes AR. Heat and moisture exchangers: structure and function. Respir Care Clin N Am 1998;4(2):261-279.

141. Ari A, Fink JB. Factors affecting bronchodilator delivery in mechanically ventilated patients. Nurs Crit Care 2010;15(4):192-203.

142. Ari A, Alwadeai KS, Fink JB. Effects of heat and moisture exchangers and exhaled humidity on aerosol deposition in a simulated ventilator-dependent adult lung model. Respir Care 2017;62(5): 538-543.

143. Svartengren M, Anderson M, Philipson K, Camner P. Human lung deposition of particles suspended in air or in helium/oxygen mixture. Exp Lung Res 1989;15(4):575-585.

144. Habib DM, Garner SS, Brandeburg S. Effect of helium-oxygen on delivery of albuterol in a pediatric, volume-cycled, ventilated lung model. Pharmacotherapy 1999;19(2):143-149.

145. Goode ML, Fink JB, Dhand R, Tobin MJ. Improvement in aerosol delivery with helium-oxygen mixtures during mechanical ventilation. Am J Respir Crit Care Med 2001;163(1):109-114.

146. Hess DR, Acosta FL, Ritz RH, Kacmarek RM, Camargo CA Jr. The effect of heliox on nebulizer function using a beta-agonist bronchodilator. Chest 1999;115(1):184-189.

147. Tassaux D, Jolliet P, Thouret M, Roeseler J, Dorne R, Chevrolet JC. Calibration of seven ICU ventilators for mechanical ventilation with helium-oxygen mixtures. Am J Respir Crit Care Med 1999; 160(1):22-32.

148. Guerin C, Fassier T, Bayle F, Lemasson S, Richard JC. Inhaled bronchodilator administration during mechanical ventilation: how to optimize it, and for which clinical benefit. J Aerosol Med Pulm Drug Deliv 2008;21(1):85-95.

149. Colebourn CL, Barber V, Young JD. Use of helium-oxygen mixture in adult patients presenting with exacerbations of asthma and chronic obstructive pulmonary disease: a systematic review. Anesthesia 2007;62(1):34-42.

150. Chowdhury MM, McKenzie SA, Pearson CC, Carr S, Pao C, Shah $\mathrm{AR}$, et al. Heliox therapy in bronchiolitis: phase III multicenter double-blind randomized controlled trial. Pediatrics 2013;131(4): 661-669.

151. Hurford WE, Cheifetz IM. Respiratory controversies in the critical care setting. Should heliox be used for mechanically ventilated patients? Respir Care 52(5):582-591, 2007; discussion 591-594.

152. Danin PE, Girou E, Legrand P, Louis B, Fodil R, Christov C, et al. Description and microbiology of endotracheal tube biofilm in mechanically ventilated subjects. Respir Care 2015;60(1):21-29.
153. Longest PW, Azimi M, Golshahi L, Hindle M. Improving aerosol drug delivery during invasive mechanical ventilation with redesigned components. Respir Care 2014;59(5):686-698.

154. Manthous CA, Khamiees M. In-line suction catheters may impede aerosol delivery to patients receiving mechanical ventilation. Chest 2000;118(3):884-885.

155. Taherian S, Rahai H, Gomez BZ, Waddington T, Bonifacio JR. Tracheal stenosis: a CFD approach for evaluation of drug delivery. Presented at ASME 2015 International Mechanical Engineering Congress and Exposition, held November 13-19, 2015, in Houston, Texas.

156. Grosz AH, Jacobs IN, Cho C, Schears GJ. Use of helium-oxygen mixtures to relieve upper airway obstruction in a pediatric population. Laryngoscope 2001;111(9):1512-1514.

157. Hess DR, Dillman C, Kacmarek RM. In vitro evaluation of aerosol bronchodilator delivery during mechanical ventilation: pressurecontrol vs. volume control ventilation. Intensive Care Med 2003; 29(7):1145-1150.

158. Guérin C, Durand PG, Pereira C, Richard JC, Poupelin JC, Lemasson $\mathrm{S}$, et al. Effects of inhaled fenoterol and positive end-expiratory pressure on the respiratory mechanics of patients with chronic obstructive pulmonary disease. Can Respir J 2005;12(6):329-335.

159. Bates J, Milic-Emili J. The flow interruption technique for measuring respiratory resistance. J Crit Care 1991;6(4):227-238.

160. Kondili E, Alexopoulou C, Prinianakis G, Xirouchaki N, Vaporidi $\mathrm{K}$, Georgopoulos D. Effect of albuterol on expiratory resistance in mechanically ventilated patients. Respir Care 2011;56(5):626-632.

161. Dhand R. Ventilator graphics and respiratory mechanics in the patient with obstructive lung disease. Respir Care 50(2):246-259, 2005; discussion 259-261.

162. Shorr AF, Zilberberg MD. The answer for inhaled antibiotics in pneumonia is still blowing in the wind. Chest 2017;151(6):12011203.

163. Anzueto A, Baughman RP, Guntupalli K, Weg JG, Wiedemann HP, Raventós AA, et al. Aerosolized surfactant in adults with sepsisinduced acute respiratory distress syndrome. N Engl J Med 1996; 334(22):1417-1421.

164. Weg JG, Balk RA, Tharrat S, Jenkinson SG, Shah JB, Zaccardelli $\mathrm{D}$, et al. Safety and potential efficacy of an aerosolized surfactant in human sepsis-induced adult respiratory distress syndrome. JAMA 1994;272(18):1433-1438.

165. Zandstra DF, Stoutenbeek CP, Miranda DR. The effect of mucolytic and bronchodilator aerosol therapy on airway resistance in mechanically ventilated patients. Intensive Care Med 1985;11(6): 316-318.

166. Fernandez R, Sole J, Blanch L, Artigas A. The effect of short term instillation of a mucolytic agent (Mesna) on airway resistance in mechanically ventilated patients. Chest 1995;107(4):1101-1106.

167. Voelker KG, Chetty KG, Mahutte CK. Resolution of recurrent atelectasis in spinal cord patients with administration of recombinant human DNase. Intensive Care Med 1996;22(6):582-584.

168. Claudius C, Perner A, Moller MH. Nebulised dornase alfa versus placebo or hypertonic saline in adult critically ill patients: a systematic review of randomized clinical trials with meta-analysis and trial sequential analysis. Systematic Reviews 2015;4:153.

169. Nava S, Compagnoni ML. Controlled short-term trial of fluticasone propionate in ventilator-dependent patients with COPD. Chest 2000; 118(4):990-999.

170. Chen WC, Chen HH, Chiang CH, Lee YC, Yang KY. Effect of salmeterol/fluticasone combination on the dynamic changes of lung mechanics in mechanically ventilated COPD patients: a prospective pilot study. Int J Chron Obstruct Pulmon Dis 2016;27(11):167-174.

171. Ernst P, Gonzalez A, Brassard P, Suissa S. Inhaled corticosteroid use in chronic obstructive pulmonary disease and the risk of hos- 


\section{Aerosol Delivery During Invasive Mechanical Ventilation}

pitalization for pneumonia. Am J Respir Crit Care Med 2007;176(2): 162-166.

172. Price D, Yawn B, Brusselle G, Rossi A. Risk-to-benefit ratio of inhaled corticosteroids in patients with COPD. Prim Care Respir J 2013;22(1):92-100.

173. Tejerina E, Frutos-Vivar F, Restrepo MI, Anzueto A, Abroug F, Palizas F, et al. Incidence, risk factors, and outcome of ventilatorassociated pneumonia. J Crit Care 2006;21(1):56-65.

174. Festic E, Carr GE, Cartin-Ceba R, Hinds RF, Banner-Goodspeed V, Bansal V, et al. Randomized clinical trial of a combination of an inhaled corticosteroid and beta-agonist in patients at risk of developing the acute respiratory distress syndrome. Crit Care Med 2017; 45(5):798-805.

175. Jaillette E, Nseir S. Relationship between inhaled $\beta_{2}$-agonists and ventilator-associated pneumonia: a cohort study. Crit Care Med 2011;39(4):725-730.

176. Dhand R. The role of aerosolized antimicrobials in the treatment of ventilator-associated pneumonia. Respir Care 2007;52(7):866-884.

177. Eschenbacher WL, Boushey HA, Sheppard D. Alteration in osmolarity of inhaled aerosols causes bronchoconstriction and cough, but absence of permeant anion causes cough alone. Am Rev Respir Dis 1984;129(2):211-215.

178. Godden DJ, Borland C, Lowry R, Higgenbottam TW. Chemical specificity of coughing in man. Clin Sci (Lond) 1986;70(3):301306.

179. Lowry RH, Wood AM, Higgenbottam TW. Effects of pH and osmolarity on aerosol-induced cough in normal volunteers. Clin Sci (Lond) 1988;74(4):373-376.

180. Miszkiel KA, Beasley R, Rafferty P, Holgate ST. The contribution of histamine release to bronchoconstriction provoked by inhaled benzalkonium chloride in asthma. Br J Clin Pharmacol 1988;25(2): 157-163.

181. Miszkiel KA, Beasley R, Holgate ST. The influence of ipratropium bromide and sodium cromoglycate on benzalkonium chloride-induced bronchoconstriction in asthma. Br J Clin Pharamcol 1988; 26(3):295-301.

182. Downes H, Hirshman CA. Calcium chelators increase airway responsiveness. J Appl Physiol 1985;59(1):92-95.

183. Beasley R, Rafferty P, Holgate ST. Adverse reactions to the nondrug constituents of nebuliser solutions. Br J Clin Pharmacol 1988; 25(3):283-287.

184. MacNeish CF, Meisner D, Thibert R, Kelemen S, Vadas EB, Coates AL. A comparison of pulmonary availability between Ventolin (albuterol) nebules and Ventolin (albuterol) respirator solution. Chest 1997;111(1):204-208.

185. Berlinski A, Waldrep JC. Nebulized drug admixtures: effect on aerosol characteristics and albuterol output. J Aerosol Med 2006; 19(4):484-490.

186. Coates AL, MacNeish CF, Meisner D, Kelemen S, Thibert R, MacDonald J, Vadas E. The choice of jet nebulizer, nebulizing flow, and addition of albuterol affects the output of tobramycin aerosols. Chest 1997;111(5):1206-1212.

187. Flament MP, Leterme P, Burnouf T, Gayot A. Influence of formulation on jet nebulisation quality of alpha 1 protease inhibitor. Int J Pharm 1999;178(1):101-109.

188. McKenzie JE, Cruz-Rivera M. Compatibility of budesonide inhalation suspension with four nebulizing solutions. Ann Pharmacother 2004;38(6):967-972.

189. Lee TY, Chen CM, Lee CN, Chiang YC, Chen HY. Compatibility and osmolality of inhaled $\mathrm{N}$-acetylcysteine nebulizing solution with fenoterol and ipratropium. Am J Health Syst Pharm 2005;62(8): 828-833.
190. Kamin W, Schwabe A, Kramer I. Inhalation solutions: which one are allowed to be mixed? Physico-chemical compatibility of drug solutions in nebulizers. J Cyst Fibros 2006;5(4):205-213.

191. Akapo S, Gupta J, Martinez E, McCrea C, Ye L, Roach M. Compatibility and aerosol characteristics of formoterol fumarate mixed with other nebulizing solutions. Ann Pharmacother 2008;42(10): 1416-1424.

192. Fok TF, Monkman S, Dolovich M, Gray S, Coates G, Paes B, et al Efficiency of aerosol medication delivery from a metered dose inhaler versus jet nebulizer in infants with bronchopulmonary dysplasia. Pediatr Pulmonol 1996;21(5):301-309.

193. Sivakumar D, Bosque E, Goldman SL. Bronchodilator delivered by metered dose inhaler and spacer improves respiratory system compliance more than nebulizer-delivered bronchodilator in ventilated premature infants. Pediatr Pulmonol 1999;27(3):208-212.

194. Fok TF, Lam K, Ng PC, Leung TF, So HK, Cheung KL, Wong W. Delivery of salbutamol to nonventilated preterm infants by metered-dose inhaler, jet nebulizer, and ultrasonic nebulizer. Eur Respir J 1998;12(1):159-164.

195. Fayon M, Tayara N, Germain C, Choukroun ML, De La Roque ED, Chêne G, et al. Efficacy and tolerance of high-dose inhaled ipratropium bromide vs. terbutaline in intubated premature human neonates. Neonatology 2007;91(3):167-173.

196. Cameron D, Clay M, Silverman M. Evaluation of nebulizers for use in neonatal ventilator circuits. Crit Care Med 1990;18(8):866-870.

197. Wildhaber JH, Hayden MJ, Dore ND, Devadason SG, LeSouëf PN. Salbutamol delivery from a hydrofluoralkane pressurized metereddose inhaler in pediatric ventilator circuits. Chest 1998;113(1):186191.

198. Graham DR, Chamberlain MJ, Hutton L, King M, Morgan WK. Inhaled particle deposition and body habitus. Br J Ind Med 1990; 47(1):38-43.

199. Ari A, Harwood RJ, Sheard MM, Fink JB. An in vitro evaluation of aerosol delivery through tracheostomy and endotracheal tubes using different interfaces. Respir Care 2012;57(7):1066-1070.

200. Mir M, Dhand R. Nebulized drug delivery in patients breathing spontaneously through an artificial airway. Respir Care 2012;57(7): 1195-1196.

201. Acute Respiratory Distress Syndrome Network, Brower RG, Matthay MA, Morris A, Schoenfeld D, Thompson BT, Wheeler A. Ventilation with lower tidal volumes as compared with traditional tidal volumes for acute lung injury and the acute respiratory distress syndrome. The acute respiratory distress syndrome network. N Engl J Med 2000;342(18):1301-1308.

202. Dubosky MN, Chen YF, Henriksen ME, Vines DL. Vibrating mesh nebulizer compared with metered-dose inhaler in mechanically ventilated subjects. Respir Care 2017;62(4):391-395.

203. Walton JS, Fears R, Burt N, Dorman HB. Intraoperative breathing circuit obstruction caused by nebulization of albuterol. Anesth Analg 1999;89(3):650-651.

204. Tonnelier A, Lellouche F, Bouchard PA, L'Her E. Impact of humidification and nebulization during expiratory limb protection: an experimental bench study. Respir Care 2013;58(8):1315-1322.

205. Davies JBS, Bromilow J. Bacterial filter obstruction with the use of ultrasonic nebulisation. Anaesthesia 2011;66(5):394-395.

206. Cunningham S, Prasad A, Collyer L, Carr S, Lynn IB, Wallis C. Bronchoconstriction following nebulised colistin in cystic fibrosis. Arch Dis Child 2001;84(5):432-433.

207. Dodd ME, Abbott J, Maddison J, Moorcroft AJ, Webb AK. Effect of tonicity of nebulized colistin on chest tightness and pulmonary function in adults with cystic fibrosis. Thorax 1997;52(7):656-658.

208. Quieffin J, Hunter J, Schechter MT, Lawson L, Ruedy J, Pare P, Montaner JS. Aerosol pentamidine-induced bronchoconstriction: 


\section{Aerosol Delivery During Invasive Mechanical Ventilation}

predictive factors and preventive therapy. Chest 1991;100(3):624627.

209. Dally MB, Kurrle S, Breslin ABX. Ventilatory effects of aerosol gentamicin. Thorax 1978;33(1):54-56.

210. Alothman GA, Alsaadi MM, Ho BL, Ho SL, Dupuis A, Corey M, Coates AL. Evaluation of bronchial constriction in children with cystic fibrosis after inhaling two different preparations of tobramycin. Chest 2002;122(3):930-934.

211. Prober CG, Walson PD, Jones J. Technical report: precautions regarding the use of aerosolized antibiotics. Committee on Infectious Diseases and Committee on Drugs. Pediatrics 2000; 106(6):E89.

212. Christiani DC, Kern DG. Asthma risk and occupation as a respiratory therapist. Am Rev Respir Dis 1993;148(3):671-674.
213. Carnathan B, Martin B, Colice G. Second hand (S)-albuterol: RT exposure risk following racemic albuterol. Respir Care 2001;46: 1084.

214. Eames I, Tang JW, Li Y, Wilson P. Airborne transmission of disease in hospitals. J R Soc Interface 2009;6(suppl 6):S697-702.

215. Hui DS, Chow BK, Chu LC, Ng SS, Hall SD, Gin T, Chan MT. Exhaled air droplet dispersion during application of a jet nebulizer. Chest 2009;135(3):648-654.

216. Dunne PJ. Economic aspects of introducing new nebulizer technology. Respir Care 2002;47(11):1321-1331.

217. Brocklebank D, Ram F, Wright J, Barry P, Cates C, Davies L, et al. Comparison of the effectiveness of inhaler devices in asthma and chronic obstructive airways disease: a systematic review of the literature. Health Technol Assess 2001;5(26):1-149. 